\title{
Advanced Good Cell Culture Practice for Human Primary, Stem Cell-Derived and Organoid Models as well as Microphysiological Systems
}

\author{
David Pamies 1, Anna Bal-Price 2, Christophe Chesné 3, Sandra Coecke 2, Andras Dinnyes 4,5, Chantra Eskes ${ }^{6}$, \\ Regina Grillari 7,8, Gerhard Gstraunthaler 9, Thomas Hartung 1,10, Paul Jennings 11, Marcel Leist 10,12, \\ Ulrich Martin 13, Robert Passier 14,15, Jens C. Schwamborn 16, Glyn N. Stacey 17, Heidrun Ellinger-Ziegelbauer 18 \\ and Mardas Daneshian 10 \\ ${ }^{1}$ Center for Alternatives to Animal Testing (CAAT), Johns Hopkins University, Bloomberg School of Public Health, Baltimore, MD, USA; ${ }^{2}$ European \\ Commission, Joint Research Centre (JRC), Ispra, Italy; ${ }^{3}$ Biopredic sarl, St Gregoire, France; ${ }^{4}$ Biotalentum Ltd, Godollo, Hungary; ${ }^{5}$ Molecular Animal \\ Biotechnology Laboratory, Szent Istvan University, Godollo, Hungary; ${ }^{6}$ Services \& Consultations on Alternative Methods (SeCAM), Magliaso, \\ Switzerland; ${ }^{7}$ University of Natural Resources and Life Sciences, Vienna, Austria; ${ }^{8}$ Evercyte GmbH, Vienna, Austria; ${ }^{9}$ Medical University Innsbruck, \\ Department of Physiology, Innsbruck, Austria; ${ }^{10}$ CAAT-Europe, University of Konstanz, Konstanz, Germany; ${ }^{11}$ Division of Molecular and Computational \\ Toxicology, Amsterdam Institute for Molecules, Medicines and Systems, Vrije Universiteit Amsterdam, Amsterdam, The Netherlands; ${ }^{12}$ In Vitro \\ Toxicology and Biomedicine, Dept inaugurated by the Doerenkamp-Zbinden Foundation, University of Konstanz, Konstanz, Germany; ${ }^{13}$ Leibniz Research \\ Laboratories for Biotechnology and Artificial Organs, Department of Cardiothoracic, Transplantation and Vascular Surgery, REBIRTH - Cluster of \\ Excellence, Hannover Medical School, Hannover, Germany; ${ }^{14}$ Department of Applied Stem Cell Technologies, MIRA Institute for Biomedical Technology \\ and Technical Medicine, University of Twente, Enschede, The Netherlands; ${ }^{15}$ Department of Anatomy and Embryology, Leiden University Medical Center, \\ Leiden, The Netherlands; ${ }^{16}$ Luxembourg Centre for Systems Biomedicine (LCSB), University of Luxembourg, Belvaux, Luxembourg; ${ }^{17}$ National \\ Institute for Biological Standardization and Control, a center of the Medicines and Healthcare Regulatory Agency, South Mimms, Hertfordshire, UK; \\ ${ }^{18}$ Toxicology, Bayer AG, Wuppertal, Germany
}

\begin{abstract}
A major reason for the current reproducibility crisis in the life sciences is the poor implementation of quality control measures and reporting standards. Improvement is needed, especially regarding increasingly complex in vitro methods. Good Cell Culture Practice (GCCP) was an effort from 1996 to 2005 to develop such minimum quality standards also applicable in academia. This paper summarizes recent key developments in in vitro cell culture and addresses the issues resulting for GCCP, e.g., the development of induced pluripotent stem cells (iPSCs) and gene-edited cells. It further deals with human stem cell-derived models and bioengineering of organotypic cell cultures, including organoids, organ-on-chip and human-on-chip approaches. Commercial vendors and cell banks have made human primary cells more widely available over the last decade, increasing their use but also requiring specific guidance as to GCCP. The characterization of cell culture systems including high-content imaging and high-throughput measurement technologies increasingly combined with more complex cell and tissue cultures represent a further challenge for GCCP. The increasing use of gene editing techniques to generate and modify in vitro culture models also requires discussion of its impact on GCCP. International (often varying) legislations and market forces originating from the commercialization of cell and tissue products and technologies are further impacting on the need for the use of GCCP. This report summarizes the recommendations of the second of two workshops, held in Germany in December 2015, aiming to map the challenge and organize the process or developing a revised GCCP 2.0.
\end{abstract}

${ }^{*}$ A report of $\mathrm{t}^{4}$ - the transatlantic think tank for toxicology, a collaboration of the toxicologically oriented chairs in Baltimore, Konstanz and Utrecht sponsored by the DoerenkampZbinden Foundation. The views expressed in this article are those of the contributing authors and do not necessarily reflect those of their institution of employment.

Received October 8, 2017; Accepted February 28, 2018; Epub April 13, 2018; ( ) The Authors, 2018

ALTEX 35(3), 353-378. doi:10.14573/altex.1710081

Correspondence: Thomas Hartung, MD PhD, Johns Hopkins Bloomberg School of Public Health, Center for Alternatives to Animal Testing (CAAT),

615 N Wolfe St., Baltimore, MD, 21205, USA

(THartun1@jhu.edu)
This is an Open Access article distributed under the terms of the Creative Commons Attribution 4.0 International license (http://creativecommons.org/licenses/by/4.0/) which permits unrestricted use, distribution and reproduction in any medium, provided the original work is appropriately cited. 


\section{Introduction}

The need for guidance on Good Cell Culture Practice (GCCP) especially for academic research was first recognized and the term GCCP was coined during a symposium of the German Association for Cell and Tissue Culture in Berlin 1996 organized by Thomas Hartung. Subsequent activities at the World Conference on Alternatives and Animal Use in the Life Sciences in Bologna 1999 (Gstraunthaler and Hartung, 1999) led to a European Centre for the Validation of Alternative Methods (ECVAM) taskforce and subsequently to a first guidance document on GCCP (Hartung et al., 2002; Coecke et al., 2005).

A new guidance document on Good In Vitro Method Practices (GIVIMP) $^{1}$, planned for 2018, aiming to reduce the uncertainties in cell and tissue-based in vitro method derived predictions in the regulatory implementation of in vitro methods for human safety assessment, is coordinated by the European validation body EURL ECVAM as a joint activity between the OECD Working Group on Good Laboratory Practice (GLP) and the OECD Working Group of the National Coordinators of the Test Guidelines Programme (WNT). It has adopted the principles of GCCP.
New technologies not included in the 2005 guidance have developed and matured in the last decade, prompting the need to update the guideline. The GCCP 2.0 collaboration was created to further promote GCCP, generate discussion and produce an updated guidance document on GCCP. These developments were fueled by individual experiences of irreproducibility of cell culture experiments, poor reporting standards and the fact that the principles enshrined in the overarching GLP $^{2}$ were developed around animal studies and were not always directly applicable to in vitro work and academic environments (Cooper-Hannan et al., 1999).

Three workshops on the application of GCCP to pluripotent stem cells (Pamies et al., 2017a), GCCP and in vitro toxicology (Eskes et al., 2017) and the one covered in the present report were organized to feed into the development of an updated guidance document (Fig. 1).

Traditional cell and tissue culture techniques have a number of challenges (Hartung, 2007; Pamies and Hartung, 2017), some of them are summarized in Figure 2. A first limitation is the origin of cell material, which especially for human cells still mostly comes from tumor cell lines or surgical tissue, which is often from diseased donors and of limited quality and quantity. Contin-

\begin{tabular}{|c|c|c|c|c|c|c|}
\hline $\begin{array}{c}\text { German Association for } \\
\text { Cell and Tissue Culture in } \\
\text { Berlin }\end{array}$ & $\begin{array}{l}\text { World Congress } \\
\text { (Bologna) }\end{array}$ & $\begin{array}{l}\text { s GCCP Guidance } \\
\text { document ECVAM }\end{array}$ & $\begin{array}{l}\text { GCCP on pluripotent } \\
\text { stem cells report }\end{array}$ & GIVIMP & $\begin{array}{c}\text { GCCP \& In Vitro Toxicology } \\
\text { ESTIV workshop }\end{array}$ & GCCP 2.0 Guidance \\
\hline 1996 & 1999 & $2002 / 2005$ & 2016 & 2016 & 2017 & \\
\hline
\end{tabular}

Fig. 1: Chronology of GCCP development

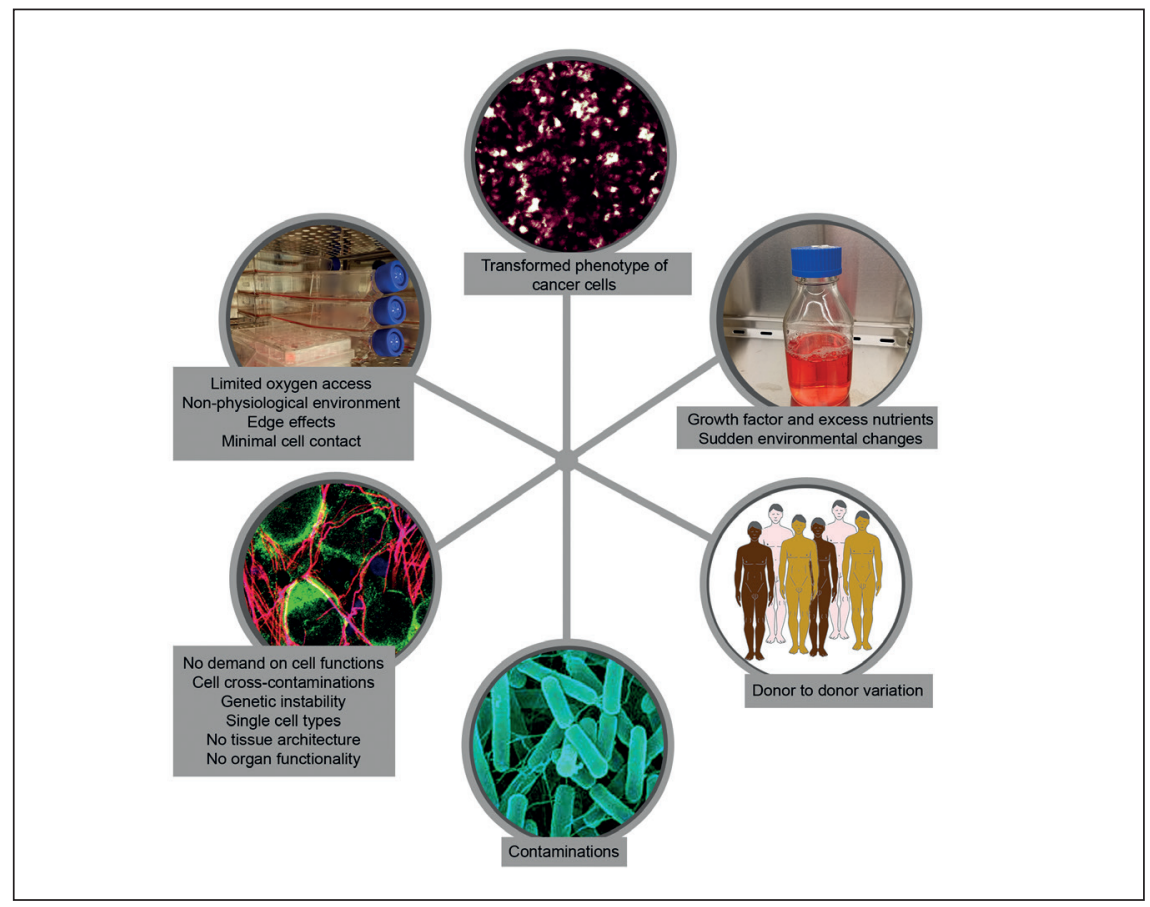

Fig. 2: Some challenges of traditional cell culture

\footnotetext{
1 http://www.oecd.org/env/ehs/testing/OECD\%20Draft\%20GIVIMP_v05\%20-\%20clean.pdf (accessed 07.10.2017)

$2 \mathrm{http}: / /$ www.oecd.org/chemicalsafety/testing/oecdseriesonprinciplesofgoodlaboratorypracticeglpandcompliancemonitoring.htm
} 
uous or prolonged culture further adds to genetic aberration and the selection of subpopulations, sometimes even observed within the same batch of cells from a cell culture bank (Kleensang et al., 2016). Contamination with other cells, most prominently HeLa cells, and with microorganisms such as mycoplasma occur more often than thought (Drexler et al., 2002; Drexler and Uphoff, 2002; Ye et al., 2015; Pinheiro de Oliveira et al., 2013). The non-homeostatic culture, which is subject to sudden media changes, requires cultured cells to maintain a phenotypic flexibility, i.e., not become terminally differentiated. The lack of demand for certain cell functions such as xenobiotic metabolism during cell maintenance further adds to the loss of expression of these functionalities. Typical cell cultures in 2D achieve 100-1000 times lower cell densities and fewer cell-cell contacts than in tissues. The lack of other cell types and spatial structures further limits the formation of organ functionalities. Oxygen supply becomes limited by diffusion through the culture medium after the first few hours, when the oxygen dissolved in the fresh medium is consumed along with other key compounds required for cell metabolism (Hartung, 2007; Pettersen et al., 2005). It is evident that these shortcomings add up to impair the extent cells can mirror physiological behavior. The lack of consideration given to the fate of applied test substances in cell culture, i.e., the in vitro biokinetics of distribution and metabolism of chemicals (Tsaioun et al., 2016), further impairs extrapolation to the in vivo situation (Hartung, 2017).

Here, two major developments in tissue culture (Stacey, 2012), namely the utilization of stem cell technologies as a cell source and 3D culture models (Haycock, 2011; Page et al., 2013; Hartung, 2014; Alépée et al., 2014; Ravi et al., 2015; Knight and Przyborski, 2015; Duval et al., 2017) including organ, organ-on-chip (Huh et al., 2011) and microphysiological systems (Marx et al., 2012,2016 ) shall be discussed with respect to their coverage in GCCP 2.0. The different technologies affect the individual principles of GCCP to different extents. Therefore, this report addresses only the most pertinent needs for revision in the following.

Lately, the standards of reproducibility that scientists adopt have been questioned as scientific data can only be reproduced at surprisingly low percentages (Begley and Ellis, 2012; Prinz et al., 2011). Therefore, with an increasing number of test systems to address specific questions, it becomes increasingly important to consider also "comparability of experimental systems" to achieve reproducibility, meaning that the most similar setup possible is used whenever addressing similar types of questions, such as the response of a certain cell or $3 \mathrm{D}$ tissue type to chemicals. Beyond that, such comparability increases the cost-efficiency of our spending in research and development, decreases the number of failures to reproduce results in other labs, and accelerates the process of generating knowledge and of innovation.

\section{Primary human cells}

Primary cultures are derived directly from excised tissue or biopsies and are cultured either as an explant culture or as a single cell inoculation after dissociation by enzymatic digestion. One definition (Ferrario et al., 2014) is that primary cultures have not been passaged after initiation, however, others define that primary cells have not been genetically manipulated either directly or indirectly (Jennings et al., 2014; Jennings, 2015). GCCP 1.0 used "The initial in vitro culture of harvested cells and tissues taken directly from animals and humans is called primary culture", which still seems adequate.

Primary cells generally have a limited lifespan in culture, ending in replicative senescence after a few passages, depending on the tissue origin as well as the particular cell type. Only a few primary systems can be subcultured several times to become a low-passage cell line. Untransformed human primary cells can sometimes be immortalized to become a continuous cell line with infinite life span. Several immortalization strategies were successfully applied and are described in the literature. Viral transformation, for example, involves the transfection of cells with viral oncogenes (e.g., SV40 large T antigen, HPV E6/E7 genes, adenoviral E1A and E1B), resulting in immortal but transformed cell lines of dedifferentiated, highly glycolytic cells. A novel immortalization strategy is the transfection of normal human primary cells with human telomerase (human telomerase reverse transcriptase, hTERT). Additionally, ectopic expression of the catalytic subunit of human telomerase (hTERT) induces immortalization, albeit maintaining the non-transformed, differentiated phenotype of the in vivo ancestor cells. In contrast, cultures from tumorigenic specimens are often immortal but transformed cells.

Although terminally differentiated cells are excised from their quiescent state to undergo multiple cell divisions in culture, normal primary cells are not genetically modified and may retain their genetic integrity, normal morphology, and most of their native cellular functions in vitro when allowed to differentiate appropriately (e.g., allowing epithelial cells to reach confluence and thus promoting contact inhibition). Thus, despite that by definition primary cultures consist of cells that have not been subcultured in vitro, vendors are often not as strict in their terminology.

Over the last decade, an impressive improvement in commercial and not-for-profit infrastructures for biobanking and access to primary cells has been observed. This has dramatically improved the quality and accessibility of primary human cells and broadened their use. The impact for a possible expansion of GCCP 2.0 to this development is discussed in the following.

\subsection{Primary cells and Principle 1: Establishment and maintenance of a sufficient understanding of the in vitro system and of the relevant factors which could affect it}

\section{Initiation of primary cell cultures}

The cells and/or the tissue of origin determine the culture conditions. In embryonic development, cells of all tissues derive from one of the three germ layers: ectoderm, mesoderm or endoderm. Therefore, when human primary cultures are established, it is essential to know from which germ layer a particular cell type originates, as this provides information about cell characteristics and physiological behavior. Depending on the tissue source, primary cultures can be initiated from physiologically normal 
tissue or from transformed cancers. This has a marked impact on the life span of the cultures. While normal primary cells have a limited in vitro life span, cell lines exhibit characteristics of transformed immortal cell lines, e.g., lack of full engagement of the p53 pathway, highly glycolytic phenotypes and inability to become contact-inhibited.

Sample acquisition from various possible sources is a crucial step in initiating a primary culture.

\section{- Post-mortem donors}

Human post-mortem donor tissue samples are most commonly comprised of non-transplantable organs kept in cold ischemia for varying lengths of time. The reasons why the organ was not transplanted must be identified, since the tissue and cells, respectively, may be pre-damaged. Furthermore, cell viability may decrease considerably with increased duration of cold ischemia.

- Organ donation

Healthy donor organs suitable for transplantation are an infrequent source of tissues/cells for primary cultures. Therefore, transplantable human donor organs are not considered here.

- Surgical specimens, biopsies, explants

Surgical specimens, tissue explants and biopsies are the most common sources of human cells for primary culture. Reference samples of healthy and diseased tissue as well as biopsies from excised tumors should be fixed for histopathological assessment. They have obvious limits as to available quantities (Stacey et al., 1998).

- Fetal tissues

Fetal or embryonic tissue, such as from surplus embryos from IVF or (spontaneous) abortions, is hardly available, and if so, there are strict ethical hurdles for research use. Human fetal and embryonic cell lines, which can be obtained with ethical and legal constraints discussed elsewhere in this report, are commercially available.

\section{- Other cell sources from healthy donors}

Voluntary donations of blood, bone marrow, skin biopsies and urinary cells, etc. represent valuable sources of human primary cells. It is important not to initiate a primary culture with cells from voluntarily donating house staff in order to prevent any re-entry of endogenous cells, especially after genetic manipulation, from the experimental set up into the donor, who may not be able to mount an immunological defense against own tissue.

The different possible sources of primary cells have advantages and disadvantages with respect to cell quality, quantity and availability. For GCCP, this implies different needs for quality control and documentation. GCCP 2.0 should include respective documentation requirements, as these can be critical for the interpretation of test results.

It is useful to keep extra material in case experiments must be repeated. Reserve tissue from the same donation or donor, however, has its limits with respect to cryopreservation of tissues. Reference samples of healthy and diseased tissue as well as biopsies from excised tumors should be fixed for histopathological assessment where possible.

Primary cultures derived from tissue explants may represent a heterogeneous mixture of cell types and cell stages. Fast-grow- ing populations, especially fibroblasts, may quickly overgrow other cells of interest. In order to initiate a more homogeneous culture, dissociated cells can be purified from a tissue suspension before seeding or are selected during culture initiation. Several methods are applicable:

- Mechanical disaggregation of soft tissue (e.g., microdissection of renal tubular fragments of nephron portions)

- Purification and/or separation of cells from a suspension by, e.g., density gradient centrifugation or immunological separation with specific antibodies coupled to magnetic beads

- Cell sorting by FACS (fluorescence-activated cell sorting) or MACS (magnetic-activated cell sorting)

- Immunodissection: primary cell isolates are seeded onto antibody-coated dishes where specific cells may firmly adhere, while other cells and cell debris can be washed off.

- Selective cell outgrowth by specific culture conditions, e.g., serum-free, chemically-defined medium supplemented with specific hormones, growth factors or cytokines, enabling growth and proliferation of specific cell types, while unwanted cells are eliminated.

- Metabolic selection by D-val-supplemented media, glucose-free media, or hyperosmolar culture conditions.

Regardless of the method employed, the initiation of a primary culture per se is a selective process. Selection may occur either by the cells' capacity to migrate from the tissue explant or, in case of dispersed cells, by their capacity to adhere to the culture substrate and subsequently to proliferate under the culture conditions applied.

Full disclosure of medium composition is a prerequisite for the reproducible quality of the model and requires defined conditions such as all media and additives.

Some problems are evident:

- How to know that the tissue is healthy or diseased?

- Quality controls to be carried out need to be defined.

- Individual differences vs. differences that are due to the differentiation stage of the source need to be distinguished.

- Time and conditions of storage between harvesting of the tissue sample and bringing it into culture.

- Lack of information about the donor affecting the variability

- Often lack of medium definition provided by manufacturers (no information on quality controls, impurities, etc.) non-defined media should be avoided, as there is no way of documenting it and variation between batches cannot be determined.

\section{Stability, functional integrity and differentiation of the system} in relation to its intended use

It is essential to characterize the cells during the different stages of culture to identify critical morphological and functional markers of changes, especially dedifferentiation, and other criteria relevant for quality control. Primary cultures are "model systems", i.e., they approximate but do not represent all aspects of the physiology of the tissue in the intact organism. Techniques employed include liquid suspension cultures, monolayer cultures, slice cultures and complex 3D culture systems (Roth and Singer, 2014), sometimes combined with microfluidic systems (Maschmeyer et al., 2015). 
The lifespan of primary cells is limited in contrast to transformed cells cultured as cell lines, and they are often difficult to cultivate due to complex requirements in terms of media, nutrients, growth factors, etc. or simply because many terminally differentiated cells do not divide (replicative senescence). The term "cultivation" when used in relation to primary cells often means maintaining, not expanding, them in culture. This is also true for the vast majority of primary tumor cells unless the cells show a high degree of transformation such as late stage melanoma cells.

When primary normal cells are isolated in early developmental stages, they may acquire morphological and functional characteristics of mature cells that mimic some stage in a more advanced normal development in culture. The term "cell differentiation" is used also for the cells returning to their usual morphology in culture after tissue dissociation and plating of the single cell suspension, a process that is to some extent repeated with every passage of cells. Not all cell types are capable of differentiation under in vitro conditions and many of them actually undergo dedifferentiation, thus losing the properties they had in situ, e.g., primary hepatocytes.

Procedures for inducing and maintaining differentiation that can be employed in model systems depend on the type of cells and the type of culture. In general, the stimulus for cell differentiation is provided by hormones or chemical agents (differentiation inducers) or by alterations in culture medium or conditions, such as growth in monolayers or in suspension as well as co-culture with other cells that initiate the pathways necessary for the subsequent changes in gene expression. Optimal conditions for cell differentiation include determination of the range of cell densities at which the cells must be seeded and grown so that they will differentiate into a more mature phenotype.

Assessment of differentiation success relies on comparing the cell morphology and the functional capabilities of the more mature cells against the undifferentiated cells. Reduction or cessation of cell proliferation, though sometimes included in the criteria for differentiation, should only be considered as confirmatory. For evaluation of cell differentiation under in vitro conditions, it is necessary to identify specific markers for different developmental windows of each cell type. The expression of these markers (at gene or protein level) should be quantified and acceptable thresholds should be defined. These values can be used as quality control reference data to improve reproducibility of experiments, as the cells respond differently to a treatment depending on the stage of cell development, differentiation and maturation. For instance, the differentiated neuronal cell population should be characterized by the expression of an appropriate level of specific differentiation-related markers including $\beta$-III-tubulin, MAP2, neurofilament 200 (NF200), while neurons at a more advanced maturation stage should show, e.g., co-localization of synapsin-I (presynaptic vesicle protein) with PSD-95 (post-synaptic protein), a reliable marker of synaptogenesis. In the case of cardiomyocytes, brachyury, $\alpha$-cardiac actin, atrial natriuretic factor and the specific sarcomeric myosin heavy chain (clone MF20) expression could be applied as markers of mature cardiomyocytes. Once a marker panel has been selected, specific quality control methods need to be established as acceptability criteria.
However, it is not sufficient to characterize cell maturation by gene/protein expression or cell morphology only. Additionally, if possible, measurements of physiological cell-specific function should be performed. For instance, in the case of neuronal phenotype, the generation of action potentials recorded by measurements of electrical activity using multi-electrode array could serve as a functional and neuron-specific endpoint. Ideally, such measurements should include not only spontaneous but also evoked activity, e.g. electrophysiological activity upon application of specific agonists and antagonists of different receptors ( $\gamma$-aminobutyric acid (GABA), N-methyl-D-aspartate (NMDA), noradrenalin (NA), 5-hydroxytryptamine (5-HT), etc.). Such measurements should refer to preset thresholds (e.g., number of spikes, bursts per minute, etc.) as a benchmark to better understand functional neuronal maturation. For epithelial or endothelial cultures, the characterization of the appropriate transepithelial and paracellular transport characteristics, which reflect appropriate transport and tissue-specific tight junction arrangement, is recommended.

In general, the measurements of cell-specific functions are more reliable than the evaluation of cell morphology, which is indicative but not conclusive. Indeed, cell morphology can be suggestive of a certain stage of differentiation, but it is difficult to interpret and of little help to the non-expert. Moreover, it is well documented that cells change morphology depending on culture conditions (media composition or extracellular matrix provided).

\section{Primary cell banking}

There is a need for guidance for the preparation of primary cells as well as tissue culture cells for archiving and banking. Biobanking of precisely defined human materials (e.g., tissue samples, biopsies, blood and body fluids, raw cells and cultured primaries) is performed to store individual reference material. This type of biobanking must be distinguished from large population studies, where high numbers of the same type of samples are collected for future use. In the latter group of bulk sampling for population studies, the individual donor will not directly benefit from participating. Here, the purpose of establishing a biobank is to gain knowledge that may benefit a specific disease group or a population at large. Research results of this kind of biobank study are usually made available by publication in scientific journals.

The contribution of industry to standardizing primary cells has been of critical importance. In recent years, almost all types of cells became available with proper documentation and quality assurance processes from commercial vendors. A more detailed discussion was not part of the workshop but will have to be considered within the process of generating and disseminating GCCP 2.0. Thus, there is now a continuous availability of high-quality human primary normal cells.

Cryopreservation is a key process for keeping stocks of original or early material to restart a culture or to identify possible changes over time. Primary cells are extremely sensitive and it can be challenging to preserve and recover cultures representative of the original material. Frozen stocks of tissue and/or blood samples of the donor should be stored, which can later be 
used for authentication or deeper analysis of genetic variations. When iPSC lines are derived from primary cultures, it is also recommended to keep stocks of the original cells, again, for authentication or when new cell lines must be derived using new reprogramming technologies.

\subsection{Primary cells and Principle 3: Documentation of the information necessary to track the materials and methods used, to permit the repetition of the work, and to enable the target audience to understand and evaluate the work}

Transparency is good practice. If information is not disclosed, this should be stated clearly and generally considered as a limitation of the system.

Tissue samples have to be pseudonymized to guarantee that the donor's name is not associated with the isolated cells at any time. A DNA profile of the tissue sample/donor should be filed or kept on record, respectively, for subsequent authentication of the primary culture and/or the cell line(s) derived thereof. Short tandem repeat (STR) analysis is the method of choice, since genes are not sequenced. If additional information on the genotype is required, analysis of single-nucleotide polymorphisms (SNPs), copy number variation (CNV) mapping, or even whole-genome sequencing can be performed.

An important part of documentation is how risks have been addressed (Section 2.3).

\subsection{Primary cells and Principle 4: Establishment and maintenance of adequate measures to protect individuals and the environment from any potential hazards}

Potential biological hazards originate from (1) the cultured cells, (2) culture media supplements, like fetal bovine serum (FBS) (van der Valk et al., 2018), and (3) the culture techniques and the experimental protocols applied, like immortalization, transformation or transfection of cultured cells. There is also the possibility that cells may be inadvertently or deliberately contaminated with pathogens after donation.

The biological risk of infected cell cultures depends on the biological risk of the (potential) infecting pathogen(s). Viral contamination needs particular attention because infection may be without cytopathic effect for the cell culture or may be latent (e.g., herpesvirus) and hard to detect. In general, the risk levels of infectious agents determine the degree of containment and the biosafety level. It is advised to culture initial primary cultures in a quarantine laboratory. When primary cells are subcultured into cell lines and subsequent diagnostic tests reveal the cultures to be uninfected, the material may be cultured together with other stocks.

A comprehensive risk assessment is mandatory and its execution and/or implementation of consequences needs to be trained.

\footnotetext{
3 https://search.coe.int/cm/Pages/result_details.aspx?ObjectlD=090000168064e8ff

4 http://eur-lex.europa.eu/LexUriServ/LexUriServ.do?uri=OJ:L:2004:102:0048:0058:en:PDF
}

\subsubsection{Hazards related to human material}

All human biopsy material carries a risk of infection and should thus be considered potentially infectious. Dangerous viruses to be considered in primary cell culture include HIV, hepatitis (A, B, C, D), Epstein-Barr virus (human herpesvirus 4), human cytomegalovirus (CMV), herpes simplex virus (HSV), varicella zoster virus, human papillomavirus (HPV), paramyxovirus, rubella virus, adenoviruses, enteroviruses/Coxsackie viruses, yellow fever virus and viral hemorrhagic fevers (VHFs) among others. Clinical donors must routinely be tested against HIV and hepatitis virus subtypes.

Human material thus must be assigned to risk level 2, which requires the handling of the material in biosafety level 2. Thus, all manipulations should be carried out in class II biological safety cabinets, providing personnel protection through containment and specimen protection in a sterile work area. The biohazard risks associated with human primary cultures can be minimized by strict adherence to aseptic techniques by trained personnel, appropriate containment levels, and defined disposal protocols.

An additional precaution is to not initiate any primary culture with cells from house staff in order to prevent any re-entry of endogenous cells into the experimenter.

\subsection{Primary cells and Principle 5: Compliance with relevant laws and regulations, and with ethical principles}

In terms of human tissue samples (e.g., biopsies, cells, blood and body fluids), international, national and/or local legal and ethical regulations have to be considered, e.g., Recommendation $\mathrm{CM} / \operatorname{Rec}(2016) 6^{3}$ of the Committee of Ministers to Member States on research on biological materials of human origin and the Human Tissues Directive $(2004 / 23 / E C)^{4}$. It is the responsibility of the individual researcher to request the required permissions and to adhere to the current legislation.

Any donation of human blood or tissue samples requires the informed consent of the donor and the approval by the local ethics committee. Confidentiality of the origin of the tissue as well as any genetic information derived from the tissue sample that might allow tracing it back to the donor must be ensured. Justification and mitigating controls should be provided in case of incomplete anonymity. For example, in case of rare diseases or origination in a specific hospital, patients may be traceable. Donors must be made aware of this and agree, or adequate non-disclosure agreements must be in place when sharing materials and data.

Ownership, intellectual property rights and patent rights must be established. It is common to establish altruistic donation with no rights of donors on the resulting materials. However, any claims on ownership of specimens or derivatives (e.g., cultured cells) by either the donor and relatives, or research institution authorities and the scientists, must be negotiated and committed in a written consent. Consent is needed on the allowed use, e.g., clarification of rights of both donors and users of the material, 


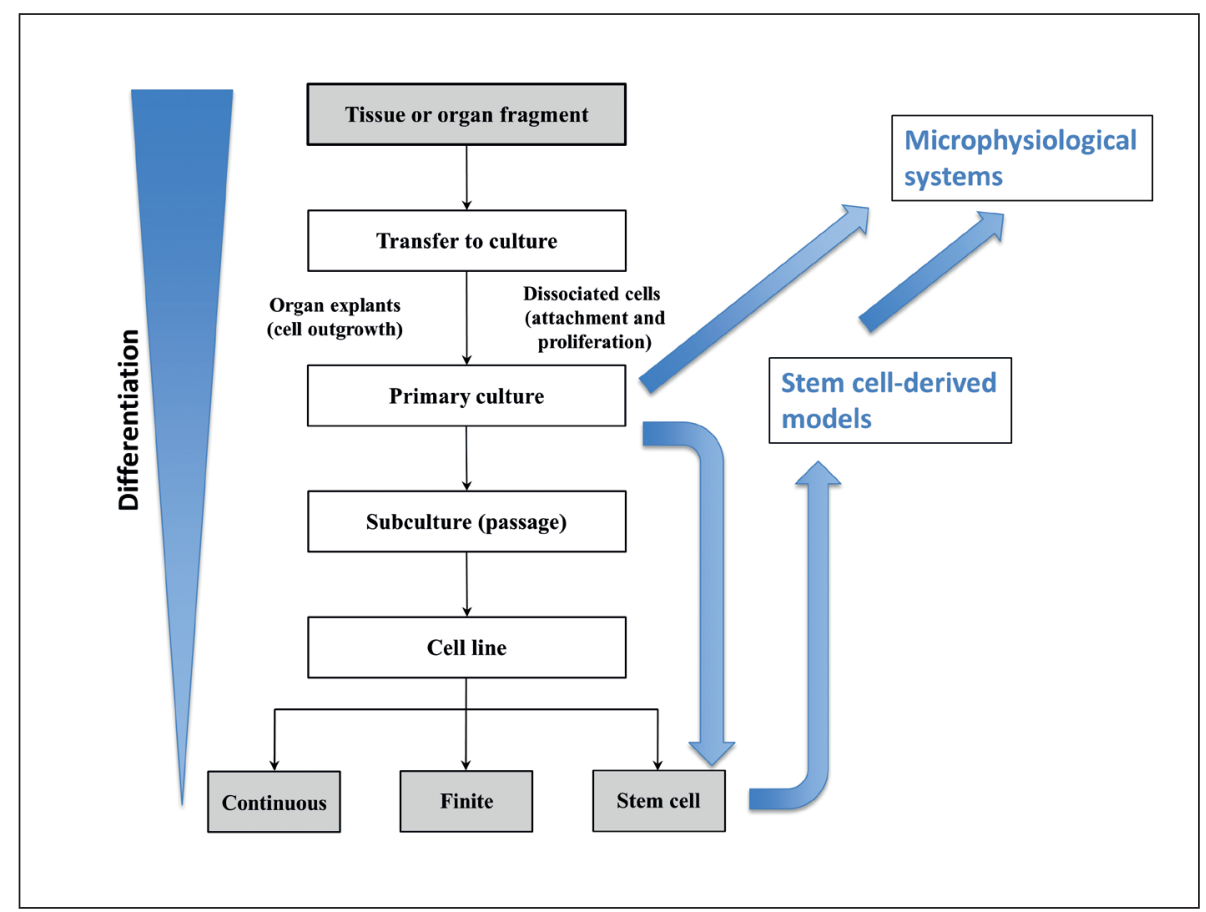

Fig. 3: From GCCP 1.0 (2005) to GCCP 2.0

The figure reproduces Fig. 1 of Coecke et al. (2005), with permission, delineating the scope of GCCP at this time and adds in blue the components covered in the present report. Please note that especially the decrease in differentiation represents an over-simplification as different primary cells show different behaviors.

commercial or non-commercial use, for research only or also non-research purposes. Most research institutions and universities offer professional assistance services.

Appropriate consent procedures must also include how to handle research results or incidental findings that are of potential interest to the donor and to his/her genetic relatives (De Clercq et al., 2017).

\subsection{Primary cells and Principle 6: Provision of relevant and adequate education and training for all personnel, to promote high quality work and safety}

All personnel involved in the preparation and culture of human primary cells must be adequately trained in the relevant techniques and in the use of appropriate equipment (biosafety level 2 ). The necessary training needs to be provided to carry out the crucial task of characterizing the tissue and cells. Laboratory personnel should be advised to strictly adhere to specific standard operating procedures (SOPs) elaborated for obtaining, processing, and maintaining human cells. This includes good aseptic techniques and good housekeeping by competent staff, a full understanding of the nature of possible contaminations, and a comprehensive contamination-monitoring program including prevention, detection and eradication procedures. Also, staff needs to obtain required medical examinations and, potentially, vaccinations.

In the cell culture laboratory, specific risks are associated with the culture work (see also Section 2.3 above). They form a critical education need for anyone working with cells, especially human and primary cultures.

Training also needs to include legal and ethical aspects (see Section 2.4), such as informed consent for use, knowledge of the rights of donors, processes to ensure confidentiality, approval processes by the local ethics committee, national and international legal and ethical regulations, risk assessment and management.

\section{Human pluripotent stem cells}

Human pluripotent stem cells (hPSC) started off with the development of human embryonic stem cells (hESC) about 20 years ago, which were then largely substituted by human induced pluripotent stem cells (hiPSC). In the following we will refer to hPSC for hESC and hiPSC together, while using the other abbreviations if relating to only one type. Stem cell lines were introduced but not covered in detail in the 2005 guidance document on GCCP (Coecke et al., 2005) and iPSC did not exist at that time. In the last decade, hPSC and their differentiation have contributed significantly to the development of "tissue in a dish" models, more recently including the organoids and microphysiological systems (MPS) to be discussed later in this report. However, it should be clearly noted that 3D cultures and MPS can be produced from continuous cell lines or primary cells. Figure 3 shows the original Figure 1 from the GCCP report (Coecke et al., 2005) and in blue the additions discussed in this workshop.

\subsection{Human embryonic stem cells}

In 1998, researchers succeeded for the first time to isolate and culture human embryonic stem cells (hESC), which were derived from blastocyst stage embryos (Thomson et al., 1998; Reubinoff et al., 2000). The capacity of these pluripotent stem cells to expand indefinitely and to differentiate into any cell type of the human body sparked their use in different research 
areas, such as stem cell-based therapy, developmental biology, disease modeling, drug discovery and toxicity screening. Since derivation of hESC lines involved destroying donated surplus early blastocyst-stage human embryos, ethical issues hindered the broad use of these cells for research, and countries have implemented different legal restrictions for the use of hESC, which further hampered the exchange of research findings and international collaborations.

\subsection{Induced pluripotent stem cells}

With a groundbreaking discovery, Takahashi and Yamanaka in 2006 reprogrammed mouse skin cells to a pluripotent state and created "induced pluripotent stem cells" or iPSC (Takahashi and Yamanaka, 2006). A year later, the same group generated human iPSC (hiPSC) from human skin cells (Takahashi et al., 2007). Similar to hESC, iPSC have the potential to differentiate into all cell types of the body. Reprogramming of somatic skin cells was achieved by introducing only four different factors (OCT3/4, SOX2, KLF4 and MYC, also known as OSKM factors). In that same year, Thomson and colleagues (Yu et al., 2007) reported reprogramming of somatic cells to iPSC by introducing an alternative cocktail mixture, consisting of the same factors OCT3/4 and SOX2 and two alternative factors NANOG and LIN28. In these first studies, human genes coding for these pluripotency-related proteins were introduced into somatic cells by lentiviral or retroviral transfection, which can potentially affect the activity of genes in the neighborhood of the integration sites. Since then, many studies have focused on optimizing the approach to enhance reprogramming efficiency and to develop genome integration-free methods. A summary with relevant references is given in Box 1. In terms of characteristics, hESC and hiPSC lines seem to be largely equivalent although epigenetic features from the original donor tissue may persist, see Box 2.

\section{Box 1: Reprogramming methods}

The first reprogrammed fibroblasts were obtained by either retroviral or lentiviral transduction of four transcription factors, yielding a $0.01-0.05 \%$ efficiency of iPSC colony formation (Takahashi et al., 2007; Yu et al., 2007). Since lentiviral particles can infect both dividing and non-dividing cells, this was the preferred approach over retroviral transduction. Although it has been shown that even fully differentiated somatic cells can be reprogrammed, the original cell population is generally heterogeneous, and the majority of cells will be incompletely reprogrammed to iPSC. Reprogramming is thought to start with an initial stochastic phase, followed by a second phase of late activation of pluripotency-related genes (Takahashi et al., 2007). The stochastic nature of the initial steps is at least partly responsible for the overall low efficiency of reprogramming. Suboptimal stoichiometry limits simultaneous expression of all 4 factors, which can be avoided by introducing all factors in a single vector. To minimize genomic integration, inserted vector DNA was flanked by bacteriophage LoxP sequences, which allows recombination between these sites in the presence of
Cre recombinase (Chang et al., 2009; Sommer et al., 2009). As a consequence, the inserted vector DNA can be largely removed, leaving only a LoxP element.

Alternatively, non-integrating viruses have been used for reprogramming, such as adenoviruses and Sendai viruses. Whereas transduction with adenoviruses yielded very low reprogramming efficiency $(0.0002 \%$ in human cells), transductions with the Sendai RNA virus resulted in a much higher reprogramming efficiency.

Besides genomic integration of viral DNA, the use of viruses requires biosafety containment level 2 , which can be downscaled to level 1 after demonstrating that viral particles are no longer present.

Other reprogramming approaches have been described (Gonzaes et al., 2011; Pamies et al., 2017a; Malik and Rao, 2013; Schlaeger et al., 2015). However, the labor-intensive methods to produce large amounts of proteins or daily transfection with mRNAs are clear disadvantages.

In addition, mimics of pluripotency-related miR-302b and/or miR372 in combination with OSKM factors yielded more efficient reprogramming (Subramanyam et al., 2011). Integration-free methods for reprogramming are now widely used. Recently, reprogramming of mouse fibroblasts to iPSC has been successful using a combination of seven small molecules (Hou et al., 2013).

\section{Box 2: Comparison of ESC and iPSC: epigenetic memory}

The improvements in reprogramming methods for hiPSC may ultimately lead to a defined, standardized and more controllable procedure for reprogramming of human somatic cells to iPSC. In addition to the different reprogramming approaches, other factors, such as the original cell source and culture conditions, may influence the properties of iPSC and phenotypic readouts.

Many studies have shown significant similarities between hESCs and hiPSCs including transcriptional profile, cell surface markers, proliferative activity and the potential to differentiate to cell types of all three germ layers. Nevertheless, variations in transcriptional and epigenetic profiles and differentiation potential have been reported among hPSC lines as well as between hiPSC and hESC lines (reviewed in Kim et al., 2010; Plath and Lowry, 2011; Liang and Zhang, $2013 a, b)$. One of the questions that emerged was whether reprogrammed hiPSC retain residual epigenetic information from the somatic cells they were derived from. Recently, it has been shown that such an epigenetic memory exists, but only for a very small number of loci (Burrows et al., 2016), and may fade on extended passage.

Using integration-free reprogramming methods (either with episomal vectors or Sendai virus) to reprogram fibroblasts and blood samples from different individuals, it was shown that most of the transcriptional and epigenetic varia- 
tion between hiPSC lines can be attributed to genetic variation (Kyttälä et al., 2016; Burrows et al., 2016). In addition, it was shown that variations in differentiation were determined by variations between donors but not by the original cell source. This information has important implications for biobanking purposes, demonstrating that fibroblasts, blood cells and most likely other easily accessible cell sources (e.g., kidney epithelial cells from urine samples) can be used for this purpose.

\subsection{Human pluripotent stem cells and Principle 1: Establishment and maintenance of a sufficient understanding of the in vitro system and of the relevant factors which could affect it}

For characterization of hPSC lines their pluripotent capacity, differentiation potential and (epi)genetic stability may be analyzed. Pluripotency is determined by analysis of gene and protein expression of pluripotency-related factors (still under discussion) by qPCR, immunofluorescence staining (e.g., TRA-1-160, SSEA-3, OSKM, Nanog), or by detailed transcriptional profiling using the PluriTest (Müller et al., 2011). Regarding differentiation potential of hPSC, it is required to show formation of derivatives of all three germ layers. Although teratoma formation following transplantation of hPSCs in immunocompromised mice has been the preferred approach, it is now clear that for ethical, economic and practically reasons (Buta et al., 2013) alternative in vitro differentiation assays are preferred. Since karyotypic abnormalities are frequently observed in 10$30 \%$ of hPSC cultures, it is an important aspect to characterize karyotype stability of established cell cultures using whole genome arrays or sequencing approaches, such as single nucleotide polymorphisms, comparative genome hybridization and exome-sequencing. Essential characterization of hPSC has been described in detail (Pamies et al., 2017a).

For differentiation of hPSC to specialized cell types (including cells from heart, brain, kidney, liver, vasculature, pancreas, immune system), similar to maintenance of hPSC cultures, it is preferable to use chemically defined media and to avoid complex biological materials of animal origin, such as FBS. In recent years, many different research groups demonstrated the production of specialized functional cell types derived from hPSC and more refined and efficient protocols have been defined for cell types representing a range of tissues (Passier et al., 2016). However, it is important to recognize that differentiated cultures often contain a mixture of different cell types and the proportions of these populations may vary between different protocols and different batches produced with the same protocol.

Use of iPSC cell lines enables the comparison of healthy and diseased cells from patients with diagnosed disorders, which were previously only available to a limited extent as hESC lines. The proof-of-principle that hPSC-derived cells reproduce disease phenotypes or drug-induced responses in vitro has now been demonstrated in a number of cases, particularly for heart and brain pathologies.

However, one of the frequently discussed disadvantages of hPSC-derived cell types is their level of maturity. In general, hPSC-derived cell types have molecular profiles and functional phenotypes that are similar to human fetal organs or cell types and thus differ from their adult counterparts. Although progress has been made to further mature hPSC-derived cell types, it is believed that controlled multicellular $3 \mathrm{D}$ or organoid-like cultures, in combination with the appropriate microenvironment, such as extracellular matrix components and biophysical mechanisms (e.g., shear stress, stretch and flow), may lead to differentiation to cell types and tissue with a more adult-like phenotype (Alépée et al., 2014; Passier et al., 2016). It is noteworthy that not all differentiation procedures would necessarily benefit from generating organoid cultures and a case in point is renal epithelial cells, which can form functional transporting tissue in 2D monolayer culture.

A number of hPSC biobanks operate to deliver reliable supplies of quality-controlled cultures. Many of the banks collaborated to establish the International Stem Cell Banking Initiative (ISCBI) ${ }^{5}$, through which they coordinate and publish consensus on best practices (Andrews et al., 2015; Kim et al., 2017). For these and other biobanking activities see Box 3 .

\section{Box 3: Biobanks for hPSC lines}

The enormous potential of hiPSC to create human models of disease and platforms for drug target discovery initiated large-scale initiatives (such as HIPSCI ${ }^{6}$, $\mathrm{StemBANC}^{7}$, $\mathrm{CIRM}^{8}, \mathrm{NYSCF}^{9}$ ) to derive hiPSC lines (Soares et al., 2014). With these, there is a growing need for international coordination to facilitate the exchange of information (e.g., donor information, reprogramming methods, culture conditions, and characterization assays) and resources, and to advance standardization and validation (Seltman et al., 2016). This is accompanied by the need to clarify ethical issues (King and Perrin, 2014). All EU-funded projects are required to register the hiPSC lines they have generated, or alternatively use only registered lines.

Large-scale initiatives for biobanking of hPSC lines have been implemented with open access for both academic and non-academic institutions. In 2007, hESCreg, a freely available registry platform for hESC lines, was established in order to provide information on hESC lines and to structure data on their background, derivation and characterization (Borstlap et al., 2008). With the first derivation of hiPSC,

\footnotetext{
5 http://www.stem-cell-forum.net/initiatives/international-stem-cell-banking-initiative/

6 http://www.hipsci.org

7 http://stembanc.org

8 https://www.cirm.ca.gov

9 http://nyscf.org
} 
the registry was expanded and renamed to $\mathrm{hPSCreg}^{10}$ and allows the global registration of hPSC lines. In 2016, it included $698 \mathrm{hESC}$ and 407 hiPSC lines from 27 countries (Seltmann et al., 2016). Other global initiatives include eagle-i ${ }^{11}$, which currently has 1,942 registered hPSC lines.

In addition, there are now a number of physical hiPSC banks such as $\mathrm{EBiSC}^{12}$ (with more than 300 disease affected lines now available), WiCell ${ }^{13}$, RUCDR Infinite Biologics $^{14}$, International Stem Cell Registry ${ }^{15}$ (1,610 hPSC lines), Coriell Institute Stem Cell Biobank and California Institute of Regenerative Medicine, which is projected to have more than 3,000 publically available iPSC lines ${ }^{16}$ in the future (Kim et al., 2017).

\subsection{Human pluripotent stem cells and Principle 5: Compliance with relevant laws and regulations, and with ethical principles}

In the Brüstle versus Greenpeace case, a patent, filed by Prof. Oliver Brüstle on the production of neural progenitor cells from ESC and their use for cell-based therapy, was challenged in 2004 by Greenpeace. In 2011, the Court of Justice of the European Union (CJEU) ruled that patenting inventions based on human embryos, defined as "capable of commencing the development of a human being-derived products", is not appropriate (Nielen et al., 2013). In other parts of the world, in Asia and the USA, there is a more liberal approach to the patentability of ESC, although in the US public funding of hESC is more restricted.

The patentability of hiPSC in Europe depends on the interpretation of the definition of a human embryo. The CJEU deferred the judgment to the national courts, which, in general, provide more freedom concerning hiPSC-based patents. This is indicated by the rulings of the German Federal Court and the UK Intellectual Property Office, which have allowed hiPSCs and their derivative technologies and inventions to be patented ${ }^{17}$.

Several institutions in the world own patents on iPSC and derivatives, which makes it very difficult to gain a clear overview of the field. The procedure of generating iPSC by Yamanaka's OSKM factor is licensed by iPS Academia Japan, which gives freedom to operate for academia, whereas license fees are required for industrial activities. The commercial application of iPSCs, especially for therapeutic applications, is indeed difficult due to the multitude of patents. In addition, other aspects need to be considered, such as use of different reprogramming tools (use of vectors, nucleases and fluorescent reporters) and whether inventions on iPSC-derivatives are also covered by protected derivation methods of iPSC.

\subsection{Human pluripotent stem cells and Principle 6: Provision of relevant and adequate education and training for all personnel, to promote high quality work and safety}

The generation of hPSCs, culture maintenance, characterization and differentiation to specific cell types require careful training. Since various technologies and protocols are available for the different steps of these procedures, this represents a true challenge for the field and complicates standardization. It is important that leading groups, institutes and organizations coordinate training in the various methods in the hPSC field, which will increase the robustness and reproducibility of methods and facilitate comparisons of research findings between groups. Several stem cell courses and workshops are listed on the website of the International Society for Stem Cell Research (ISSCR ${ }^{18}$ ).

HiPSC and derivatives, cultured as simple or more complex models including single or multicellular organoids (see below), therefore now offer or are suggested for a wide range of potential applications in basic research and applied preclinical and clinical sciences (Fig. 4). They allow - at least theoretical - access to various types of healthy human cells and tissue models in unlimited quantities. GCCP for hPSC has been extensively described (Pamies et al., 2017a). Therefore, here we only briefly outline some of their uses, which illustrate the corresponding challenges for GCCP, in Box 4.

Related to the use of hPSC lines for development of drug toxicology screening assays, a Good In Vitro Method Practice (GIVIMP) guidance document ${ }^{1}$ has been produced by EURL ECVAM. The purpose of GIVIMP is to contribute to increased standardization, harmonization and overall quality of in vitro studies that inform test item safety assessment in a regulatory context. Its focus is thus narrower than GCCP 2.0, but it aims for the arguably higher standard of GLP and incorporates GCCP as a key component.

Challenges, issues and recommendations concerning the use of hiPSC in different organotypic culture models will be discussed in detail in the following section.

\section{Box 4: Applications of hPSC lines}

Basic research into organ development

One application may be investigating differentiation and development in basic research, e.g., the requirements for certain differentiation pathways, by applying molecular knockdown techniques or using chemical inhibitors. Such basic research may increase the understanding of in vivo development and thus in turn improve differentiation pro-

$10 \mathrm{http}: / /$ www.ebisc.org/

$11 \mathrm{https} / / /$ www.eagle-i.net

12 http://www.ebisc.org/

$13 \mathrm{http}: / /$ www.wicell.org/

$14 \mathrm{http}: / /$ www.rucdr.org/stem-cell

15 http://www.umassmed.edu/iscr

$16 \mathrm{https} / / /$ catalog.coriell.org/1/CIRM

$17 \mathrm{http}: / /$ amsdottorato.unibo.it/7739/1/JAMIL_ARIF_TESI.pdf

$18 \mathrm{http}: / /$ www.isscr.org/home/events/training-courses 


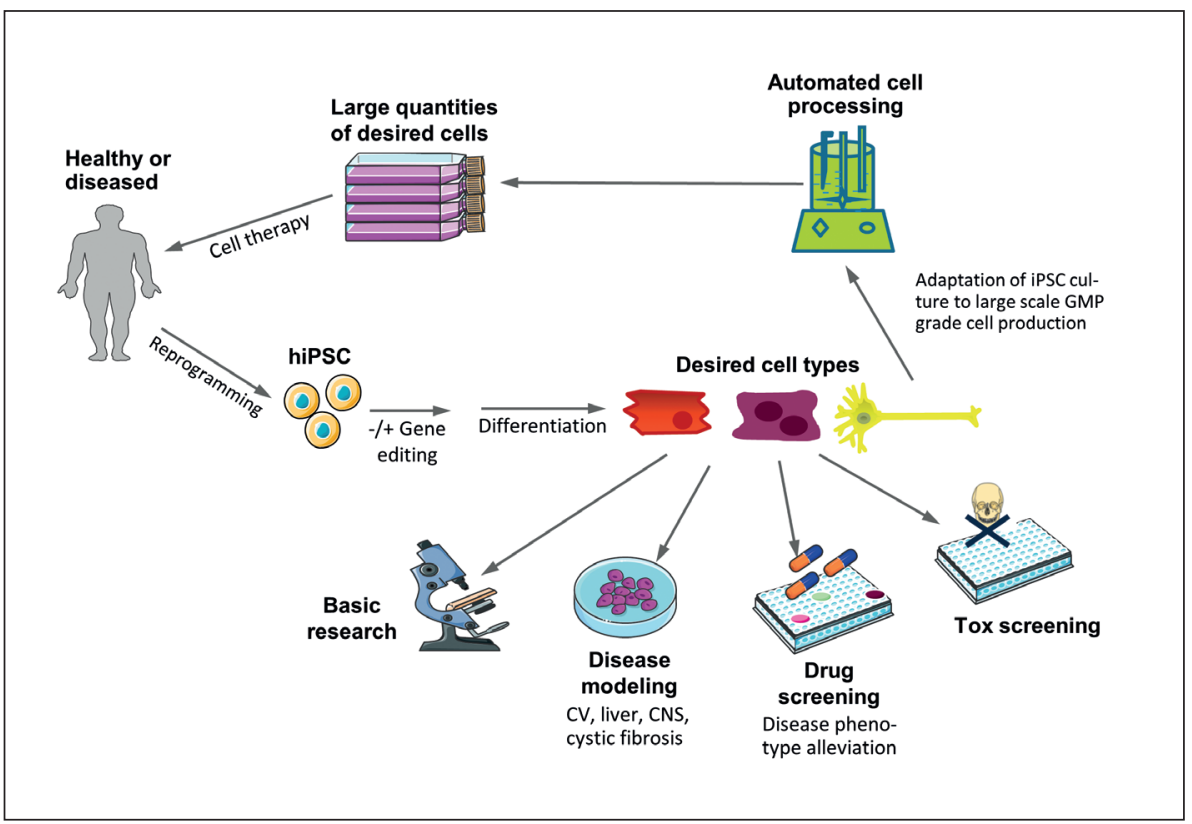

Fig. 4: Derivation, differentiation and various potential applications of human induced pluripotent stem cells (hiPSC)

The figure was produced using Servier Medical Art, drafted by Asifiqbal Kadari.

tocols. The basic research area may also shed light on the potential functions of noncoding RNAs and epigenetic modifications in differentiation and development, which have been recognized as important cellular regulators in recent years (Fatica and Bozzoni, 2014).

Disease modeling and drug screening

A rather wide area, in which hPSC and their derivatives are already employed and suggested to have real impact, is in disease modeling for basic disease understanding and screening of new drugs (Bellin et al., 2012; Avior et al., 2016). Disease modeling may start with generation of patient-specific hiPSC through reprogramming of patients' cells or separately from cells of healthy volunteers. In case of monogenic diseases, for which the responsible genes are known, the reprogrammed hiPSC may be subjected to gene editing using recently developed tools (Cox et al., 2015), e.g., the disease mutation may be reverted to wild-type in the patient-derived hiPSC, or the mutations suggested or known to cause the disease may be introduced into hiPSC from healthy donors (see also Section 6 on gene editing).

One could also consider introducing certain genomic regions, which were identified as linked to certain diseases in genome wide association studies (GWAS) into wild-type hiPSC. Such genomic regions may represent transcriptional regulatory regions or non-coding RNAs rather than genes encoding single proteins. Similarly, exposure to toxic and infectious agents as well as endogenous signaling molecules can be used to introduce disease-like states in culture, similar to the respective animal models.

Use of hiPSC in regenerative medicine

Currently, most respective clinical trials are using hESC-de- rived cells, e.g., hESC-derived retinal pigment epithelial (RPE) cells to treat macular degeneration (Kimbrel and Lan$\mathrm{za}, 2015)$. The use of RPE cells in cell therapy is especially attractive since the eye is a largely immunepriviledged site able to tolerate non-histocompatible cells. Other disease areas with ongoing clinical trials include hESC-derived pancreatic endoderm for type I diabetes, and hESC-derived oligodendrocyte progenitors for spinal cord injury (Kimbrel and Lanza, 2015). The use of precursor cells instead of more differentiated cell types for implantation may be possible and potentially advantageous in the area of regenerative medicine, since there is evidence in preclinical research that such precursor cells differentiate further within the organ environment and even become vascularized, as reported for transplantation of liver buds into mouse models with liver disease to treat liver failure (Takebe et al., 2014).

Besides the use of hESCs as starting material for tissue engineering applications, also hiPSCs have gained great interest. This is especially true since hiPSCs can be derived patient-specifically, allowing autologous applications without the need for immunosuppression. The first clinical study on application of hiPSCs-derived RPE cell sheets was approved in 2013 by the Japanese regulatory authorities. Since then one patient was treated with an autologous RPE cell-sheet transplant in 2014 and the government approved a follow up study with allogeneic hiPSC-derived single cell RPE transplants in 2017.

Despite this progress, major challenges remain for successful application of stem cells in regenerative medicine including their potential to form tumors, the requirements for Good Manufacturing Practice (GMP), and the scrutiny required to test efficacy and potential side effects, to name just a few. Since these approaches employ rather extensive 
cell culture to expand and prepare the cells for grafting into patients, they are underpinned by the principles to be summarized in GCCP 2.0.

\section{Drug and toxicity screening}

Since hiPSCs can be continuously expanded in culture in an undifferentiated state and then differentiated to form virtually all cell types of the human body, they are suggested to be an unlimited source of primary-like cells of human origin, which are especially advantageous for use in toxicity screening in comparison to the usually relatively dedifferentiated cell lines (Scott et al., 2013; Kolaja, 2014). A major issue in this context, however, is the mostly still fetal phenotype of the differentiated cells, which limits their ability to reflect in vivo mechanisms. This limitation may be of less importance when using hiPSC cells for developmental toxicity screening or evaluating effects of compounds on differentiation in general, since these applications do not rely on a fully mature differentiated cell (West et al., 2010; Kameoka et al., 2014; Rempel et al., 2015).

\section{Microphysiological systems and organ-on-chip technologies}

This chapter revisits the fundamental principles of GCCP in order to illustrate the challenges to cover the more complex bioengineered cell culture models in GCCP 2.0.

\subsection{Microphysiological systems and Principle 1: Establishment and maintenance of a sufficient understanding of the in vitro system and of the relevant factors which could affect it}

A broad description of MPS has been part of a previous report (Pamies et al., 2017a). However, due to the increase of applications and use of these systems, a more detailed description can be found in this section. This chapter addresses mainly the most common MPS grown either free-floating in typical cell culture conditions or in micro-devices using microfluidics technology (organ-on-a-chip approach) (Zhang and van Noort, 2011; Marx et al., 2012, 2016; Ghaemmaghami et al., 2012; van Duinen et al.,
2015; Perestrelo et al., 2015; Balijepalli and Sivaramakrishan, 2017). Here we use the term "microphysiological system" synonymous to and including often-used terms such as organoids or spheroids (Achilli et al., 2012; Fatehullah et al., 2016). We define an MPS as a complex cell culture model, which mimics an organ, or defined parts of an organ, in aspects of structure and function. MPS typically consist of several cell types, which are spatially and functionally organized similar to their organization in a normal organ. MPS are often three-dimensional but in principle do not have to be. Increasingly, organoids are derived from pluripotent stem cells or multipotent stem cells (Zhang et al., 2017). Examples of MPS are intestinal organoids (Sato et al., 2009), liver (Bhushan et al., 2013; Yoon et al., 2015; Ware and Khetani, 2017), kidney (Wilmer et al., 2016), cerebral organoids (Lancaster et al., 2013; Hogberg et al., 2013; Pamies et al., 2017b) and midbrain organoids (Monzel et al., 2017), while organ-on-chip cultures have been achieved, e.g., for neuronal tissue of the brain (Kilic et al., 2016; Moreno et al., 2015).

Although both free-floating organoids and organ-on-chip cultures can be summarized under the term MPS, it is important to highlight that there are differences. These include that the size of free-floating MPS is usually limited by the perfusion of nutrients into the structure, while organ-on-chip MPS have a physical size limit, which is defined by the micro-device in which they grow. Additionally, organ-on-chip MPS typically depend on a flow of medium (microfluidics), while free-floating MPS are surrounded by or placed on top of medium either under static or dynamic (shaking or rocking) conditions. Importantly, MPS are also a form of organotypic culture, which also include organ slices, whole organ cultures and cultures of primary cells (even with mixed cell populations), which similarly aim to reproduce or maintain organ functionality. Noteworthy, no agreed terminology exists for these approaches, but some distinctions in use of terms can be noted (Tab. 1).

\subsection{Microphysiological systems and Principle 2: Assurance of the quality of all materials and methods, and of their use and application, in order to maintain the integrity, validity, and reproducibility of any work conducted}

The culture of MPS depends on the use of certain non-biological materials. These range from normal cell culture plastic to more

Tab. 1: Approaches, terminologies and typical distinguishing features in organotypic culture

\begin{tabular}{|c|c|c|c|c|c|c|c|}
\hline Technology & $\begin{array}{l}\text { Organ } \\
\text { structure }\end{array}$ & $\begin{array}{l}\text { Organ } \\
\text { functionality }\end{array}$ & 3D & Multi-cell & Multi-organ & Perfusion & Homeostasis \\
\hline $\begin{array}{l}\text { Microphysiological } \\
\text { systems (MPS) }\end{array}$ & Usually & YES & YES & YES & $\mathrm{NO}$ & Possible & $\begin{array}{l}\text { If recirculating } \\
\text { perfusion }\end{array}$ \\
\hline $\begin{array}{l}\text { Organoids, } \\
\text { spheroids }\end{array}$ & Often & Some & YES & Some & NO & $\mathrm{NO}$ & NO \\
\hline Organ-on-chip & Often & YES & YES & Some & $\mathrm{NO}$ & YES & $\begin{array}{l}\text { If recirculating } \\
\text { (rare) }\end{array}$ \\
\hline $\begin{array}{l}\text { Multi-organ-, } \\
\text { body- or } \\
\text { human-on-chip }\end{array}$ & Often & YES & YES & Some & YES & YES & $\begin{array}{l}\text { If recirculating } \\
\text { (rare) }\end{array}$ \\
\hline
\end{tabular}


advanced, treated cell culture materials like ultra-low adhesion plates and customized perfusion chambers (Marx, 2012; Li et al., 2012; Li and Cui, 2014). It is of crucial importance to validate the compatibility of these materials with the investigated MPS. Aspects like release of substances, toxicity, impact on differentiation and function, adhesive capacity or potential absorption of proteins and small molecules from the culture medium need to be considered.

For organ-on-chip culture, an additional level of complexity is introduced by the utilization of pumps, tubes and, potentially, integrated sensors. Particularly for the tubes and sensors, which are in contact with the medium and cells at the same time, considerations as described above are required. Use of pumps and tubes also always includes the danger of leakage, a safety issue that can also easily become a source of especially bacterial contamination of the model.

Various kinds of extracellular matrices are used both for floating MPS as well as for organ-on-chip cultures. The compatibility of these matrices with the cell culture material needs to be ensured. The utilized matrices include materials like Matrigel ${ }^{\mathrm{TM}}$, laminin, collagen, Geltrex ${ }^{\mathrm{TM}}$ or Vitronectin ${ }^{\mathrm{TM}}$. Depending on the application, it has to be considered whether a xeno-free (i.e., avoiding non-human animal materials) culture is necessary, whether the utilized matrix shall contain growth factors, whether batch variations are acceptable, and where the generation of these materials is a burden to animal welfare. These issues are primarily driven by the desire to make the culture system better defined and therefore more suited to standardization.

Work with MPS has some particular challenges that make their standardization more demanding and therefore require the use of GCCP even more. These challenges stem from their complexity and the fact that they often require extremely long differentiation times. This complexity can be associated with variability between individual MPS experiments, thus affecting reproducibility of the MPS quality and functionality and hence any downstream readouts. Ways to address this are high degrees of standardization in the procedure, including seeding, maintenance, induction of differentiation, etc., as well as rigorous quality checks and standardization attempts with the starting cell population, typically stem cells (Stacey et al., 2016). Further variations often arise from variances in the number of cells used at the start, which require consistent cell counting approaches and reproducible cell loading methods. Furthermore, because of the spatial organization and asymmetry of MPS, readouts that are based on small sensors might in fact only be readouts for a sub-part of the MPS and not the whole structure. Therefore, the use of non-invasive sensors that, e.g., measure the oxygen consumption in the medium or the release of soluble factors such as neurotransmitters may be advisable. Finally, cryopreservation is way more complex for MPS than for standard cell culture models. It has to be ensured that MPS fully retain their functionality after thawing; this can be done with various methods including analysis of cell death and organ-specific functionalities (e.g., metabolic activity of hepatocytes, contraction of cardiomyocytes, or the ability to fire action potentials for neurons).

An emerging field that is not discussed further here is bioprinting (Hong et al., 2017; Fricain et al., 2017). The printing of complex organ-like structures with multiple cell types in a defined spatial organization is an exciting development, which will allow new approaches and certainly also requires the use of GCCP.

\subsection{Microphysiological systems and Principle 3: Documentation of the information necessary to track the materials and methods used, to permit the repetition of the work, and to enable the target audience to understand and evaluate the work}

The work with MPS requires similar documentation efforts as work with stem cells and their derivatives described above. MPS have the peculiarity that they are often cultured for prolonged periods of time, which obviously requires careful documentation. Since MPS mimic organ functions, it is important to document, which organ functionalities are expected, how they are tested and what the outcomes of these tests are.

Particularly organ-on-chip MPS require additional documentation, which includes information about the utilized device, including information about the material, and technical specifications. Among these specifications, the medium flow rate in microfluidics devices is of particular importance because, together with the information about the frequency of media addition, it allows estimating the nutritional support of MPS.

\subsection{Microphysiological systems and Principle 4: Establishment and maintenance of adequate measures to protect individuals and the environment from any potential hazards}

Typically, MPS nowadays originate from stem cells. Hence their utilization requires the same ethical considerations as all work with stem cells (Balls, 2012). This is particularly evident with the use of hESC but also applies to hiPSC lines, which are derived from living donors. Furthermore, MPS derived from human iPSCs are personalized models, specific to the donor of the sample that was used for iPSC generation. Again, this has ethical implications that must be covered by the informed consents as these donors are often still alive and possibly identifiable.

In terms of ethics, brain-MPS might require special consideration. After the publication of cerebral organoids (Lancaster et al., 2013), there was an intense debate whether such complex brain-like structures with potentially physiologically relevant neuronal connections give rise to specific ethical considerations (Pera et al., 2015; Anonymous, 2015). The debate centers on the question whether these kinds of MPS have the ability to "think and/or sense". While there seems to be a consensus in the field that this is not the case with current models, particularly also because sensory input and output are missing, this will be a hot topic for the future as further advanced MPS are developed.

\subsection{Microphysiological systems and Principle 6: Provision of relevant and adequate education and training for all personnel, to promote high quality work and safety}

Concerning educational issues, MPS represent a chance to foster interdisciplinary research and training. MPS are at the interface of biology and material sciences. Therefore, engineers working 
with MPS need at least a basic understanding of the underlying biology, while biologists and biotechnologists need to learn and understand the constraints and possibilities that certain materials and devices have. Additionally, questions from classical physics, like flow dynamics, become relevant for MPS grown in shaken cultures or microfluidics devices. This kind of interdisciplinary training should be included in modern curricula for biologists and biotechnologists. Additionally, training for already established researchers could be organized via specialized workshops, continued education, etc. In summary, working with MPS requires an interdisciplinary educational background, which should be conveyed to the current and next generation of scientists.

\section{High-throughput and high-content screening}

The term "high-throughput" is often interchanged with "high-content", although they rarely mean the same thing. High-content technologies include "omics" approaches such as transcriptomics, metabolomics, proteomics, lipidomics and epigenomics (van Vliet, 2011) as well as imaging technologies (van Vliet et al., 2014). These techniques simultaneously measure hundreds to hundreds of thousands of endpoints, capturing large parts of the biological status of a model. While the through-put of these techniques is indeed increasing at a steady rate, mostly due to lowering costs and increasing supply of service laboratories, they are still not considered high-throughput. Cost is not the only issue; high-content technologies are extremely data-rich and need a considerable amount of time and expertise for data processing. However, the advantage of these technologies is that they are usually non-targeted and holistic. This is important as it means that experiments are hypothesis-free and unbiased, which is ideal for, e.g., investigating the effects of chemical and nanoparticle exposure. In fact, this technology, particularly transcriptomics, has paved the way for modern mechanistic science. The more we understand about biology, the more it allows us to transfer some of these end-points into high-throughput targeted assays.

For the most part, omics technologies utilize samples harvested from a pool of cells. This is not only due to detection limits, but also owed to the fact that cell culture usually employs cell numbers of 10,000 to 2 million cells per treatment group. This is important physiologically, as the majority of cell types work together at a tissue-like level of organization and cannot and should not be used in isolation. Also, since there is a certain heterogeneity in cell culture, it is also useful to measure a mean response, thus increases in a certain response may suggest to be occurring in more than (for example) $5 \%$ of the cells. However, a distinct disadvantage in these approaches exists when heterogeneity is uncontrolled and not desired. As already mentioned above, this is the case at the moment for many iPSC differentiation protocols, where non-target mixed cells can give false results (i.e., non-target cell responses) in high-content omics approaches. In addition, these protocols are by nature temporal and have a window of vulnerability for (toxicological) exposure. This window is often not defined, which greatly increases variance in experiments. A lot more work on defining windows of vulnerability and controlling temporal alterations in control cells is needed.

High-throughput, as opposed to high-content, typically only measures one to five endpoints, but can do this repeatedly in many samples. The advantage is that we usually know a lot about these endpoints. Thus, there is little informatics work after data collection. Data streams are simple and manageable, which facilitates rapid decision-making. However, caution is advised as to the overuse of cytotoxicity assays, as we have been applying viability and apoptosis assays for decades with little progress in their acceptance as alternative methods. Thus, the selected high-throughput endpoints should give information pertaining to the mechanism of chemical perturbation. This can be achieved by investigation of organelle disturbances, for example with micronuclei assays, or measuring mitochondrial integrity, endoplasmic reticulum disturbances and endocrine modulations.

However, experimentors must also be careful when employing live staining dyes as these, by their very nature, can interfere with biological processes. A technique gaining ground is to introduce reporter genes into cells, preferably with the natural upstream promoters of the genes of interest. Reporter cell lines enable expression to be followed over time and potentially into recovery in a single experiment, thus greatly enhancing throughput for repeat-dose long-term experiments. Whilst a

Tab. 2: Examples of high-content and high-throughput techniques*

\begin{tabular}{|l|l|}
\hline High-content & High-throughput \\
\hline DNA and RNA sequencing & Multi-electrode arrays \\
cDNA arrays & Impedance \\
Epigenomics & Temporal alterations in supernatant metabolites (e.g. glucose and lactate) \\
Proteomics & Temporal alterations in supernatant biomarkers \\
Metabolomics & Fluorescent reporter assays \\
High-content imaging & Automated imaging techniques \\
\hline
\end{tabular}

* New technologies are developing that permit relatively high throughput sequencing of single cells, e.g., single cell sequencing. Such technologies will become increasingly accessible and affordable for researchers and will open new possibilities to analyze complex cell populations. 
new reporter cell line has to be generated for every reporter, it is possible to reduce experimental repetitions by mixing cell lines or by multiplexing reporters.

On the other hand, it is sometimes also useful to analyze single cell responses. Also, utilizing high-throughput imaging systems (or confusingly termed high-content imaging) to analyze qualitative and quantitative alterations in chemical-induced reporter activity can be helpful. This, coupled with the ability to have multiple exposures, multiple concentrations, and hundreds to thousands of compounds applied over extended time periods, reaches dimensions not yet possible with modern high-content approaches.

High-throughput and particularly reporter systems are very attractive to the iPSC community. This combination allows the generation of reporter cell systems that can be differentiated into any cell type. It also offers the possibility of monitoring differentiation and analysis of subpopulations of responses. High-content approaches are catching up in this regard, for example single-cell-transcriptomics is now possible but still not affordable for screening many chemicals at different concentrations and in a repeated dose regime.

Examples of high-content and high-throughput techniques can be found in Table 2. Whilst these are clearly not in the direct remit of a GCCP document, it is important that appropriate quality standards are adopted in the generation of such data and its handling and storage, where such standards exist.

\section{Gene editing}

Gene editing has already been briefly addressed in a previous report (Pamies et al., 2017a), however, this section presents more detailed information about the possible problems and challenges of gene editing practices. For many years, the development of technologies enabling efficient genetic modification of primary cells, immortalized cell lines and especially hPSCs was a critical hurdle for the development of cellular in vitro assays for disease modeling, drug identification and screening, safety pharmacology and toxicology. In fact, efficient and site-specific genetic engineering was urgently required to facilitate cellular in vitro assays in basic research and high-throughput screening procedures including orthogonal screenings to reduce false-positive candidate hits. This includes (1) the introduction of reporter and selection genes, (2) the generation of gene knockouts, (3) the genetic correction of mutations in control cell lines or (4) the targeted introduction of disease specific mutations.

At least in case of primary cells and hPSCs, efficient protocols for plasmid transfection were not available, and gene transfer into these cells was possible only using viral and especially lentiviral vectors (Gropp et al., 2003). Although even inducible (Benabdellah et al., 2011) or cell type-specific expression (Gruh et al., 2008) from different viral vectors was reported, such techniques do not allow site-specific genome engineering. Moreover, transgenes are lost over time in case of non-integrating vectors, or the introduced transgenes frequently undergo silencing in undifferentiated cells or during differentiation. Although genetic elements have been identified that minimize silencing effects
(Ackermann et al., 2014), silencing of lentiviral vectors is still a problem. Nevertheless, in case of primary cells, viral vectors are still state of the art, mainly because their proliferative capacity hardly allows isolation of transgenic single cell clones.

In the meantime, lipofection protocols (Liu et al., 2009) and new electroporation technologies including nucleofection (Siemen et al., 2005) have been developed that enable efficient plasmid transfection (Templin et al., 2012) and generation of hPSC lines with more stable transgene expression (Schwanke et al., 2014). Although typically less silencing is observed in hPSCs after random integration of expression plasmids than after lentiviral transduction, these approaches still rely on random integration of the introduced genetic elements and more or less unpredictable integration-site dependent expression of the transgene. Moreover, insertional mutagenesis may lead to altered cell function.

A more specific but laborious alternative is the classic technique of gene targeting, which has been well established in murine ESC for decades (Waldman, 1992). This approach utilizes the cellular homologous recombination (HR) pathway (Chapman et al., 2012). After transfection of a donor plasmid carrying a selectable transgene flanked by homologous DNA stretches of substantial length, HR leads to targeted insertion of the transgene cassette into the favored locus. However, low targeting efficiencies and challenging culture characteristics have prevented classic gene targeting in hPSC from becoming broadly applicable. Furthermore, positive and negative selection markers are indispensable to identify the rare targeting events among the typically much more frequent off-target events (Vasquez et al., 2001).

These issues have only been overcome by the recent advance in genetic engineering with the introduction of customized engineered endonucleases in terms of zinc-finger nucleases (ZFNs), transcription activator-like effector nucleases (TALENs) and clustered regularly interspaced short palindromic repeat (CRISPR) RNA guided nucleases (Box 5). The generation of cell lines carrying transgenes (Box 6) is an important application of genome editing. The ability to correct mutations in patient-specific iPSC is of high relevance for cellular in vitro assays (Box 7). Similarly, gene knockout and introduction of disease-specific mutations (Box 8) represent increasingly important tools to study the genetic basis of disease and gene functions.

\section{Box 5: Designer nucleases for targeted genome engineering}

Customized engineered endonucleases include zinc-finger nucleases (ZFNs), transcription activator-like effector nucleases (TALENs) and clustered regularly interspaced short palindromic repeat (CRISPR) RNA guided nucleases. These designer nucleases enable locus-specific introduction of double strand breaks (DSB). These targeted DSB activate endogenous cellular DNA repair mechanisms including non-homologous end joining (NHEJ) and homologous recombination (HR) (Chapman et al., 2012; Choulika et al., 1995; Rouet et al., 1994). NHEJ and HR can then be utilized to efficiently introduce the intended genetic modifications nearby the generated double strand break. 
Meanwhile, designer nuclease technology, in particular based on the CRISPR/Cas system, has successfully been applied to genetically modify immortalized cell lines, hPSCs and even primary cells like fibroblasts (Howden et al., 2015). These technologies not only allow efficient gene inactivation through NHEJ, but also enhanced HR-based gene targeting (Cho et al., 2013; Porteus and Carroll, 2005; Miller et al., 2011; Merkert and Martin, 2016).

\section{Box 6: Generation of transgenic cell lines}

Transgenes that confer cellular functions or visualisze these through reporter genes represent an important application of genome editing in immortalized cell lines and hPSCs. For instance, halide-sensitive variants of yellow fluorescent protein have been developed that allow automated measurement of the activity of the cystic fibrosis transmembrane regulator (CFTR) (Galietta et al., 2001); $\mathrm{Ca}^{2+}$-sensitive fluorescent proteins directly visualize calcium fluctuations in the cell (Tallini et al., 2006).

In general, primary cells are not amenable to gene editing as their short replicative lifespan does not allow isolation of single cells and re-expansion of monoclonal cell lines to levels that can be banked, characterized and that then still have sufficient proliferation capacity to serve as a model system. Therefore, one of the model systems as close to primary cells as possible that can still be engineered are human telomerase- or SV40 conditionally-immortalized cell lines. Proof of principle that such cells still maintain primary cell characteristics is given by knock-out of CD46 in the hTERT immortalized cell line RPTEC/TERT1 (Wieser et al., submitted).

In case of hPSCs, cell lines carrying reporter or selection genes are indispensable for the enrichment of distinct cell lineages after stem cell differentiation for monitoring of stem cells and their progenies in vitro and in vivo. Such lines can be generated either by targeted integration into a so-called "safe harbor site" by applying tissue-specific or constitutive promoters, or by targeted integration into the endogenous locus of interest. Besides the application of safe harbor loci, the placement of reporter elements under the control of endogenous loci is also highly facilitated by the use of designer nucleases.

\section{Box 7: Gene correction in} patient-specific (stem) cells

Whereas some years ago iPSC lines from family members and their differentiated derivatives were considered optimal internal controls, gene-corrected isogenic control cell lines now represent the state of the art in disease modelling and drug screening. To date, gene correction in patient-derived human iPSCs using designer nucleases has been accomplished for various monogenetic diseases either by genotypic correction of the underlying defective endogenous gene or by insertion of a functional gene into a safe harbor locus.

Direct genetic correction of disease-related mutations by nuclease-based HR is typically more challenging, but can be accomplished with or without leaving footprints in the genome. This approach is generally preferable to insertion of additional wild type cDNAs at other genomic positions or insertion of foreign genetic elements such as antibiotic resistance genes into the endogenous locus, since footprint-less gene correction of the endogenous locus should also lead to normal gene regulation. One of the authors demonstrated the feasibility of footprint-less targeting without antibiotic selection through targeted insertion of a novel restriction site into the AAVS1 locus using TALEN technology and a single stranded oligonucleotide (Merkert et al., 2014).

\section{Box 8: Gene knockout and introduction of disease-specific mutations}

Immortalized cell lines overexpressing transgenes of interest that carry disease-specific mutations have been used successfully for many years in disease modelling and drug screening, for instance in case of cystic fibrosis (Welsh and Smith, 1993; Verkman et al., 2006). Although more laborious than simple insertion of mutated transgenes, the generation of knockout lines or the targeted integration of specific mutations into iPSCs for the establishment of isogenic disease models is definitely of great significance for medical research and drug screening. Depending on the HR efficiency in a cell line of interest, classical gene targeting in an immortalized cell line often may be quite simple. On the other hand, low transfection and targeting efficiencies as well as difficulties in single cell cloning prevented classical HR-based gene targeting from becoming broadly applicable in hPSCs. Only the development of designer nucleases resulting in a substantially increased frequency of targeted homologous recombination finally facilitated gene targeting in hPSCs.

For closer modeling of other genetic diseases that do not represent a knockout, the editing of just a few nucleotides is necessary. This was reported for the introduction of disease-associated point mutations in the $\alpha$-synuclein gene (Parkinsons disease), the AKT2 gene (insulin resistance) or the ApoE gene (Alzheimer's disease), respectively (Ding et al., 2013a,b; Gonzalez et al., 2014). For modelling of the mitochondrial cardiomyopathy of Barth syndrome, a specific mutation was introduced into the TAZ gene of iPSCs (Wang et al., 2014), and for mimicking amyotrophic lateral sclerosis, a mutation was introduced in the human SOD1 locus (Yu et al., 2015). In principle, scar-less gene-targeting can be applied to the integration of specific mutations as well as for gene correction. This has the advantage of keeping the natural endogenous gene regulation intact, which is often mandatory for disease modelling and drug screening. 
Regardless of this stunning progress in genome engineering, there are still key issues that have to be solved for application of these technologies in disease modeling and drug development. Importantly, the level of off-target effects of designer nucleases is still not fully defined. This is especially the case for the different CRISPR/Cas systems. In view of recent contradictory studies (Fu et al., 2013; Hsu et al., 2013; Mali et al., 2013; Pattanayak et al., 2013; Veres et al., 2014) and the ongoing development of improved CRISPR/Cas9 systems (Fu et al., 2014; Slaymaker et al., 2016), it will be essential to develop standard approaches for assessment of off-targets and to obtain a reliable comparative estimation of the off-target efficacy or vice versa the level of confidence of the different types of designer nucleases.

In case of hiPSCs, the question of the most adequate controls is still controversial. Current genome engineering technologies now offer the opportunity to generate controls, which have, at least in theory, exactly the same genomic background as the corresponding diseased iPSC clone. However, similar to differences between primary iPSC clones, gene editing with the inevitable selection of correctly targeted single cell clones apparently also leads to phenotypic differences that have to be considered. Whether these differences that are observed in undifferentiated iPSC clones also extend to functionality of their differentiated derivatives has to be evaluated. Furthermore, it is still not clear whether these variances are mainly due to epigenetic differences or due to genomic variations in individual cells based on off-target effects of the applied designer nucleases. As a consequence, however, it is mandatory to analyze several transgenic iPSC clones and their functional derivatives, and to carefully evaluate resulting data.

The developments in genome engineering have the potential to substantially change the design of in vitro assays applied for investigation of disease mechanisms, for automated high-throughput drug screening, and for safety pharmacology and toxicology. This invaluable impact will further increase when combined with iPSC technology that allows production of sufficient patient-derived cell material for basic biomedical research and drug development. Reporter and selection genes can be placed at specific sites of the genome leading to well-defined transgene expression levels or cell type-specific expression, which in case of iPSCs substantially facilitates improvement of differentiation protocols and cell enrichment. Moreover, even footprint-less correction or insertion of disease-specific single nucleotide mutations is possible, which will improve the data quality of in vitro assays. It is thus foreseeable that targeted genome engineering will revolutionize medical research and drug development.

\section{International and legal aspects - beyond EU and US}

This report is very much driven by the experiences of the workshop participants coming from the EU and the US. Legislation around the world shows great diversity, often reflecting the maturity of the legal system and the scientific field in the respective country. Although GCCP is not required under any national laws, there are diverse guidelines, regulations and laws that resonate with different GCCP aspects such as storage of donor cells and tissues, genetic manipulation, safety and development of biomedical products (Pamies et al., 2017a).

\subsection{Legal aspects for human tissue and stem cells}

In case of human tissue, the ethical procurement procedure may vary between different legal jurisdictions. In some countries, legal requirements exist for procurement of tissues for research (e.g., UK Human Tissues Act, 2004), while other countries seem to be less regulated. Dhar and Hsi-en Ho (2009) have summarized some of the differences among countries including Singapore, China, Brazil and Mexico. There are big differences in the use restrictions in different countries. For example, while China has one of the most unrestrictive stem cell policies, the UK presents one of the most complete regulations.

Globally, legislation in many developing countries is also fighting commercial activities that use stem cells for treatments without proper efficacy, safety and quality controls in so-called "stem cell clinics". Countries such as China and Thailand have made considerable progress in reducing the "grey zone" activities of such commercial entities. In many countries, however, the legislative changes are much slower than the technological advances. Only in August 2015, China's National Health and Family Planning Commission approved a regulation on stem cells in clinics. There is a risk that stigmatization of the stem cell field could occur due to illegal activities using a similar terminology and making exaggerated promises.

Japan, as one of the most advanced countries in the research and translation towards clinical applications, has adjusted its legal regulations to the progress of the field in order to allow faster progress for the benefit of the patients. There are several guidelines for human ES/iPS cells in Japan such as Guidelines on the Derivation of Human Embryonic Stem Cells ${ }^{19}$, Guidelines on the Distribution and Utilization of Human Embryonic Stem Cells ${ }^{20}$, or Guidelines on the Research on Producing Germ Cells from Human iPS Cells or Human Tissue Stem Cells ${ }^{21}$.

Other governments such as Brazil are very restrictive on the use of human cells and their derivatives for clinical research: ANVISA (Agência Nacional de Vigilância Sanitária - National Health Surveillance Agency) in 2011 established the minimum requirements for Cell Technology Centers (CTC) to be able to use human cells and their derivatives for clinical research purposes and/or therapy. Only CTC can work with somatic cells, germ cells, adult stem cells, ESC and iPSC, for clinical research and/or therapy. Brazilian CTC are national institutions and are very low in number.

\footnotetext{
19 http://www.lifescience.mext.go.jp/files/pdf/n1553_01r2.pdf

20 http://www.lifescience.mext.go.jp/files/pdf/n1553_02r2.pdf

21 http://www.lifescience.mext.go.jp/files/pdf/n1567_02r2.pdf
} 


\subsection{Border issues to transfer and commercialize human-derived products}

Differences in legislation can favor or hinder the incorporation of GCCP practices. On the one hand, economic difficulties to buy reagents or tests may limit the use of GCCP recommendations in the laboratory. On the other hand, government regulation can restrict access to certain materials and services that can reduce or slow down GCCP application. For example, legislation in Brazil entails a very strict control on human-derived products that slows down Brazilian research work and can directly affect GCCP. In particular, commercialization of cell-based products of human origin is difficult. In addition, import barriers exist including tax costs and long delays. Products are retained by customs without appropriate storage conditions. This example is not meant to single out one country but shows that in highly relevant economies hurdles not experienced in others can exist.

GCCP acknowledges these local and jurisdictional situations and prescribes that where such issues affect a researcher's ability to pursue GCCP, then the researcher should attempt to mitigate the impact on the quality of work by additional controls or procedures.

\subsection{International aspects other than legislation}

Important non-legislative forces working to improve the situation include the scientific and clinical societies, who continuously discuss best practices and standards, e.g., towards stem cell research and clinical applications. For example, the International Society for Stem Cell Research (ISSCR) is promoting a discussion and spread of best stem cell research and clinical translation practices and safety measures around the globe ${ }^{22}$, together with many national or regional associations, among them the Australasian Society for Stem Cell Research (ASSCR), the Japanese Society for Regenerative Medicine, the Korean Society for Stem Cell Research, Stem Cells Australia, the Stem Cell Society Singapore (SCSS), the Taiwan Society for Stem Cell Research, the Israel Stem Cell Society (ISCS), the Brazilian Association for Cell Therapy, the New York State Stem Cell Science Program (NYSTEM), the New York Stem Cell Foundation (NYSCF), the Stem Cell Network (SCN), the Danish Stem Cell Society (DASCS), the German Stem Cell Network (GSCN), the German Society for Stem Cell Research e.V. (GSZ), the Norwegian Center for Stem Cell Research (NCSCR), the Stem Cell Network North Rhine-Westphalia, and the Associazione di Biologia Cellulare e del Differenziamento (ABCD). National scientific and clinical societies need to actively interact with each other, with national and international legislators, patient and advocacy organizations and the media, as the use of stem cell technologies for research and regenerative medicine will require new standards and approaches.

National and international grant agencies, such as the European Commission, have already started to fund projects promoting such activities, for example EuroStemCell ${ }^{23}$, but further measures will be needed, as there is a high risk that early failures in therapy or sensitive elements of the technologies including human gene editing and use of embryonic stem cells could create potential backlashes and hard-to-overcome obstacles. A plethora of good quality educational resources on stem cells is available online ${ }^{24}$.

Another important element is improvement of the information available on existing cell lines via stem cell registries, for example the European human Pluripotent Stem Cell Registry ${ }^{10}$, the European Bank for induced pluripotent Stem Cells (EBISC) Innovative Medicines Initiative project ${ }^{12}$, the European Collection of Authenticated Cell Cultures (ECACC) ${ }^{25}$, or the Cellosaurus ${ }^{26}$ projects. In addition, consortia such as the International Stem Cell Banking Initiative facilitate and publish consensus on best practice relating to stem cell culture banking and testing (Andrews et al., 2015; Kim et al., 2017).

In the age of internet and social media, various public sites are very important for information and opinion forming, including professional and patient-driven blogs, for example "the Niche" by Dr Paul Knoepfler ${ }^{27}$. LinkedIn groups (among many for example Stem Cell Clinical Trials, Regenerative Medicine Group, Cell Therapy Industry Group, Stem Cell Research, Serum-free cell and tissue culture) and Facebook groups and sites (for example Stem Cells and Tissue Engineering, Stem Cells, Molecular Medicine, Cancer Biology, Biotech Entrepreneurship, Stem Cell and Regenerative Science) are also genuine although non-moderated sources of personal experiences and opinions.

However, media presence of rogue clinics and treatments is also strong, as patients are often recruited via websites for unauthorized clinical treatments and popular media campaigns are used to put pressure on legislators and authorities via biased public opinion (for example the Stamina Foundation campaign in Italy ${ }^{28}$ ). Education of the public on how to distinguish genuine from fraudulent information and internet providers and authorities to regulate and limit the latter would be particularly important.

\subsection{GCCP in a global industry}

Some efforts to introduce GCCP and alike to the industrial sector have been made. Good practices and quality assurance schemes are in general applied here more regularly. GCCP wants to contrast from GLP, being more generally applicable as a minimum standard for underpinning good practice to be

22 http://www.isscr.org

$23 \mathrm{http}: / /$ www.eurostemcell.org/

$24 \mathrm{http}: / / w w w . e u r o s t e m c e l l . o r g / s t e m-c e l l-r e s o u r c e s$

$25 \mathrm{https}$ ://www.phe-culturecollections.org.uk/collections/ecacc.aspx

26 http://web.expasy.org/cellosaurus

$27 \mathrm{http}: / /$ www.ipscell.com

$28 \mathrm{http}: / /$ www.nature.com/news/italian-stem-cell-trial-based-on-flawed-data-1.13329 
met by any laboratory. Parts of industrial research, which are more exploratory in nature, where GLP requirements would be prohibitive to advance research, also can benefit from "lighter" standards. One example is the "Guidance for Industry: Current Good Tissue Practice (CGTP) and Additional Requirements for Manufacturers of Human Cells, Tissues, and Cellular and Tissue-Based Products (HCT/Ps)"29. This guidance document makes a compilation of the requirements for complying with FDA regulation $21 \mathrm{CFR} 1271^{30}$, which mainly focuses on industry. In the guidance, specification such as how to perform a validation study, control the labeling of the products and compile documentation are included. Another example that may be useful from the field of advanced cell and gene therapy medicinal products is the EMA "Reflection paper on stem cell-based medicinal products" (EMA, 2011), which addresses the definition and identification of stem cells as well as characteristics of different stem cell types. In particular, it provides general quality considerations (such as starting materials, manufacturing process and process validation) as well as characterization and quality controls (identity, purity, potency, tumorigenicity and genomic stability) that could be useful.

In case of production of controlled single tissue or organ culture in bioreactors, control of the bioreactor process operations can be, per se, a means of ensuring cell culture quality control (Rebelo et al., 2016). In this specific case, regulatory requests to industry have gradually moved from the validation concept of "exhaustive product characterization" to "rigorous and detailed process characterization". It represents the "quality-by-design" concept in which the quality of the end-product is defined by its process of production. Here the critical elements of the end product (i.e., critical quality attributes, CQAs) are defined (e.g., differentiation, purity, functionality, etc.). Based on this, the process parameters that critically impact these CQAs (i.e., critical process parameters, CPPs) are identified (e.g., medium composition, temperature, time of cultivation, critical raw materials, vessels, etc.). A design space is then defined in which it is demonstrated that the parameters of the process operations can vary without affecting the quality of the system. Finally, a control strategy can be undertaken in case variations are observed. A recent application of these principles is the EMA "Guideline on process validation for the manufacture of biotechnology-derived active substances and data to be provided in the regulatory submission", which entered into force in November 2016 (EMA, 2014). WHO recommendations on the evaluation of cells for the manufacture of biomedical products (WHO, 2010) also endorse and reference the GCCP principles.

\section{Commercial tools}

Reproducibility is the most important requirement of scientific experimental results, meaning - summarized simply - same set- up and same reagents give same results. Some degree of this comparability has been striven for and has been implemented to some degree in various fields like transcriptomic data with the MIAME standards (Brazma, 2009), cell-based assay ontogeny (Sakurai et al., 2016), cell imaging with the initiative of open microscopy environment (Goldberg et al., 2005) or the open source skin equivalent (Frankart et al., 2012). Commercialization of technologies includes their standardization and dissemination, often with the respective training and the formation of user communities. All of this supports the reproducibility of scientific work.

\subsection{Balancing of scientific and commercial interests}

Such comparability within the whole scientific community can only be reached when all reagents and procedures are well documented by the users. However, when commercial tools are used, we often encounter the problem of using "black box" kits or reagents including cells of unknown source or function. This fact counteracts the idea of GCCP as different labs use different reagents without knowing the exact composition or cellular functionality, decreasing "comparability" of the results. Therefore, fulfilling criteria for GCCP - unlike all other issues mentioned above, which solely depend on the scientists - also depends on a second party, i.e., the commercial providers. Thus, we are facing opposing interests between the scientific community that wants, and in many instances needs, to know, e.g., the components of the kits they use versus the commercial providers who have incurred development costs for the tools - with the idea of having a competitive product on the market - and need to keep an advantage of their products by keeping the ingredients or amounts of ingredients secret. Facing this discrepancy between "open source concepts" versus problems of cost-effectiveness and competition of companies with permanent pressure for innovation and better products, we still have to strive for fewer (or no) black boxes, balancing the interests of both sides, provider and user. At the same time, GCCP could be promoted by vendors who could claim to be "GCCP-compliant" and refer to respective papers in their flyers and certificates of analysis of the products.

\subsection{GCCP requirements on commercial tools}

In the quest to mimic the human system as well as possible by in vitro models the complexity of necessary reagents has increased significantly. We here restrict ourselves to the most important elements of the cell culture system (cells, media, plastic and extracellular matrix). The information on these elements that needs to be provided by the manufacturer must be extended to all other commercial products including highly complex ones such as scaffolds or microfluidic devices. Material safety data sheets, certificates of analysis, as well as protocols describing the exact handling of the material represent the minimal requirements.

\footnotetext{
29 https://bit.ly/2kKzPxy

30 https://www.accessdata.fda.gov/scripts/cdrh/cfdocs/cfcfr/CFRSearch.cfm?CFRPart=1271
} 


\subsection{Commercial cells and Principle 1: Establishment and maintenance of a sufficient understanding of the in vitro system and of the relevant factors which could affect it}

The range of different commercially available cell types is increasing quickly and has opened research into new fields and offered new opportunities. Due to the enormous need for human cell cultures, many companies have started to offer cells as research tools, yet the degree of documentation provided with the different available cells varies greatly. The state of primary cells depends much on the isolation and culture process before use and providers should make efforts to reveal this. For cell lines provided by cell banks this information is also often incomplete, including origin, derivation, as well as passage number / population doubling level after isolation of the cells from tumor cells or from other sources. What may contribute to non-reproducibility issues is that the way the cells function in a given environment will impact on their epigenomic profiles (well demonstrated now in several cases), meaning that the functions of the cells may be significantly different from one lab to another.

Whereas much effort has been put into harmonizing and standardizing the omics techniques, very few inter-laboratory and inter-group analyses have been published, with the notable exception of transcriptomics. It is time to elaborate "minimal information for cell provision" (MICP) that is essential for product release to the market. Provision of information on cell type-specific characteristics as well as absence of contaminations with regards to bacteria, fungi and human pathogenic viruses for appropriate risk assessment of a specific cell line is important. In this regard, there is a high need for harmonization of test methods used, as well for the definition of which human pathogenic viruses have to be tested for in which tissue source. The more information on the original material used for cell isolation is given, the better. Additionally, ethical standards have to be followed remembering that differences still exist between countries and harmonization must be achieved. At the moment it is to be expected that information provided might differ between companies located in different countries owing to different ethical standards. For cell line authentication, information on the STR profile is an accepted option.

Information should be provided routinely on (see also Coecke et al., 2005):

- cell source / donor, approval of responsible ethical committee

- incl. details of the informed consent, e.g., whether RNA sequencing would be allowed for transcriptomics investigations or DNA sequencing for analysis of epigenomic profiles

- establishment of cell culture, especially important for hiPSCs, 3D cell culture (e.g., scaffolds, ECM)

- age, characteristics, functions, authentication of cell culture

- protocols for cell culture propagation: medium composition, oxygen supply, split ratio

- protocols for freezing / thawing

Nevertheless, in many cases only having more information than today will not be sufficient to solve reproducibility is- sues, which do not come only from the provider. Users cannot escape their responsibility for their own "due diligence" and screening for the best media (there may be large differences between providers for the supposedly same culture medium), serum (if (fetal) calf or human serum is used) (van der Valk et al., 2018), cell sources (if the user relies on external sources) and matrix (if any is employed). After finding the right catalogue numbers, a batch-to-batch selection process will be necessary for the highly critical and variable (with respect to performance) products. The cells have to be "fit for purpose" and this has to be tested in each lab, and thus the responsibility lies in the respective lab.

\subsection{Commercial cells and Principle 2: Assurance of the quality of all materials and methods, and of their use and application, in order to maintain the integrity, validity, and reproducibility of any work conducted}

In order to achieve comparability, the use of defined and disclosed cell culture media is necessary. Therefore, as outlined above, an agreement between scientist and commercial provider has to be reached for provision of proprietary information on cell culture media composition. Disclosure under CDA is a solution when the user has a precise question about the content of a given set of ingredients. The user also may complete this information from patent applications. Further, (non-)governmental authorities like journals, politics, funding agencies, could exert pressure for a detailed description of the composition of defined media. Additionally, media often contain serum or other non-defined additives such as bovine pituitary extract that, due to their nature, are prone to batch-to-batch variations, strongly influencing the outcome of experiments.

As cell culture media are improved regularly, any changes in the composition (qualitatively as well as quantitatively) have to be communicated to the customer and new developments should be defined as a new, improved product with certain characteristics. Most importantly, standardization and definition of cell culture media and matrices for cellular adherence also represents the first step towards potential clinical applications of scientific data.

It may be illusory to believe that the providers are in possession of all the information that may be needed by the users because often the final provider to the customers does not fully control products and there is a number of partners in the supply chain. For example, the medium producer will often source amino acids and vitamins from outside the company and will have only a partial picture of the impurities contained in those ingredients. Of course, the situation is better under Good Manufacturing Practice regimens for cell therapy products, but the costs are on a different scale, as the cost of quality controls becomes dominant in that case. This is also true for extracellular matrices, especially of biological origin, such as Matrigel ${ }^{\mathrm{TM}}$.

Scientists also need detailed information on the culture ware used. There are several examples of products derived from different commercial distributors strongly influencing cellular fate 
such as, e.g., the differentiation capacity of certain stem cells. Nevertheless, in the culture plastics, the entrants are fewer in number and the surface treatments by plasma gases are relatively controlled. Therefore, plastics are less of an issue nowadays. Still there remain uncertainties about the expiry dates of those products since the effects of surface modification are temporary. Moreover, the resulting surface modifications remain dependent on the process and the quality controls rely on chemical and physical controls, and are not sufficient in all cases to explain the batch-to-batch variations. Here again, the users have a duty to perform their own quality control and pre-use batch testing with their appropriate assay systems.

\section{Next steps}

This workshop held in December 2015 in Konstanz, Germany and the subsequent joint elaboration of this report highlights recent significant developments in cell culture and in vitro test models with regard to the need for best practice. It builds on and updates the recommendations of the earlier guidance (Coecke et al., 2005) and preliminary discussions on this updating process arising from an initial workshop in Baltimore, USA in 2015 (Pamies et al., 2017a). The outcome of the Konstanz workshop stimulated a symposium at ESTIV 2016, which also led to a publication (Eskes et al., 2017) and further symposia to open up the discussion on the requirements for a new GCCP document (GCCP 2.0) are planned in 2018 (e.g., at Society of Toxicology Annual Meeting 2018). The authors, who represent different views on the value chain of cell research of both reports, agreed on the need to promote and improve standardization, quality assurance and reporting of in vitro work. The combined views, which do not necessarily represent a consensus on each and every aspect, are not yet at the level of actual guidance. It is intended that an expert group that has been formed by drawing on authors from this and the earlier reports will draft GCCP 2.0. This will be based on the original guidance and integrate the respective workshops and the parallel development of in vitro reporting standards. This process will also involve gathering broader expert opinion from a range of stakeholders. In order to facilitate this activity, the Good Cell Culture Practice Collaboration has formed a secretariat at CAAT and interested parties are encouraged to contact the secretariat.

\section{References}

Achilli, T. M., Meyer, J. and Morgan, J. R. (2012). Advances in the formation, use and understanding of multi-cellular spheroids. Expert Opin Biol Ther 12, 1347-1360. doi:10.1517/147 12598.2012.707181

Ackermann, M., Lachmann, N., Hartung, S. et al. (2014). Promoter and lineage independent anti-silencing activity of the A2 ubiquitous chromatin opening element for optimized human pluripotent stem cell-based gene therapy. Biomaterials 35, 1531-1542. doi:10.1016/j.biomaterials.2013.11.024
Alépée, N., Bahinski, T., Daneshian, M. et al. (2014). Stateof-the-art of 3D cultures (organs-on-a-chip) in safety testing and pathophysiology. ALTEX 31, 441-477. doi:10.14573/ altex1406111

Andrews, P. W., Baker, D., Benvinisty, N. et al. (2015). Points to consider in the development of seed stocks of pluripotent stem cells for clinical applications. Regen Med 10, 2 Suppl, 1-44. doi: $10.2217 / \mathrm{rme} .14 .93$

Anonymous (2015). Do we need an ethics of self-organizing tissue? Nat Methods 12, 895. doi:10.1038/nmeth.3618

Avior, Y., Sagi, I. and Benvenisty, N. (2016). Pluripotent stem cells in disease modelling and drug discovery. Nat Rev Mol Cell Biol 17, 170-182. doi:10.1038/nrm.2015.27

Balijepalli, A. and Sivaramakrishan, V. (2017). Organs-on-chips: Research and commercial perspectives. Drug Discov Today 22, 397-403. doi:10.1016/j.drudis.2016.11.009

Balls, M. (2012). Ethical issues in the production of human cell lines and stem cell lines. Altern Lab Anim 40, 59-61.

Begley, C. G. and Ellis, L. M. (2012). Drug development: Raise standards for preclinical cancer research. Nature 483, 531533. doi:10.1038/483531a

Bellin, M., Marchetto, M. C., Gage, F. H. and Mummery, C. L. (2012). Induced pluripotent stem cells: The new patient? Nat Rev Mol Cell Biol 13, 713-726. doi:10.1038/nrm3448

Benabdellah, K., Cobo, M., Munoz, P. et al. (2011). Development of an all-in-one lentiviral vector system based on the original TetR for the easy generation of Tet-ON cell lines. PLoS One 6, e23734. doi:10.1371/journal.pone.0023734

Bhushan, A., Senutovitch, N., Bale, S. S. et al. (2013). Towards a three-dimensional microfluidic liver platform for predicting drug efficacy and toxicity in humans. Stem Cell Res Ther 4, Suppl 1, S16. doi:10.1186/scrt377

Borstlap, J., Stacey, G., Kurtz, A. et al. (2008). First evaluation of the European hESCreg. Nat Biotechnol 26, 859-860. doi: 10.1038/nbt0808-859

Brazma, A. (2009). Minimum information about a microarray experiment (MIAME) - Successes, failures, challenges. Scientific WorldJournal 9, 420-423. doi:10.1100/tsw.2009.57

Burrows, C. K., Banovich, N. E., Pavlovic, B. J. et al. (2016). Genetic variation, not cell type of origin, underlies the majority of identifiable regulatory differences in iPSCs. PLoS Genet 12, e1005793. doi:10.1371/journal.pgen.1005793

Buta, C., David, R., Dressel, R. et al. (2013). Reconsidering pluripotency tests: Do we still need teratoma assays? Stem Cell Res 11, 552-562. doi:10.1016/j.scr.2013.03.001

Chang, C. W., Lai, Y. S., Pawlik, K. M. et al. (2009). Polycistronic lentiviral vector for "hit and run" reprogramming of adult skin fibroblasts to induced pluripotent stem cells. Stem Cells 27, 1042-1049. doi:10.1002/stem.39

Chapman, J. R., Taylor, M. R. and Boulton, S. J. (2012). Playing the end game: DNA double-strand break repair pathway choice. Mol Cell 47, 497-510. doi:10.1016/j.molcel.2012.07.029

Cho, S. W., Kim, S., Kim, J. M. and Kim, J. S. (2013). Targeted genome engineering in human cells with the Cas9 RNA-guided endonuclease. Nat Biotechnol 31, 230-232. doi:10.1038/nbt.2507 
Choulika, A., Perrin, A., Dujon, B. and Nicolas, J. F. (1995). Induction of homologous recombination in mammalian chromosomes by using the I-SceI system of Saccharomyces cerevisiae. Mol Cell Biol 15, 1968-1973. doi:10.1128/ MCB.15.4.1968

Coecke, S., Balls, M., Bowe, G. et al. (2005). Guidance on good cell culture practice - A report of the second ECVAM task force on good cell culture practice. Altern Lab Anim 33, 261287.

Cooper-Hannan, R., Harbell, J. W., Coecke, S. et al. (1999). The principles of good laboratory practice: Application to in vitro toxicology studies - The report and recommendations of ECVAM Workshop 37. Altern Lab Anim 27, 539-577.

Cox, D. B., Platt, R. J. and Zhang, F. (2015). Therapeutic genome editing: Prospects and challenges. Nat Med 21, 121-131. doi:10.1038/nm.3793

De Clercq, E., Kaye, J., Wolf, S. M. et al. (2017). Returning results in biobank research: Global trends and solutions. Genet Test Mol Biomarkers 21, 128-131. doi:10.1089/gtmb.2016.0394

Dhar, D. and Hsi-En Ho, J. (2009). Stem cell research policies around the world. Yale J Biol Med 82, 113-115.

Ding, Q., Lee, Y. K., Schaefer, E. A. et al. (2013a). A TALEN genome-editing system for generating human stem cell-based disease models. Cell Stem Cell 12, 238-251. doi:10.1016/j. stem.2012.11.011

Ding, Q., Regan, S. N., Xia, Y. et al. (2013b). Enhanced efficiency of human pluripotent stem cell genome editing through replacing TALENs with CRISPRs. Cell Stem Cell 12, 393-394. doi:10.1016/j.stem.2013.03.006

Drexler, H. G. and Uphoff, C. C. (2002). Mycoplasma contamination of cell cultures: Incidence, sources, effects, detection, elimination, prevention. Cytotechnology 39, 75-90. doi:10.1023/A:1022913015916

Drexler, H. G., Uphoff, C. C., Dirks, W. G. and Macleod, R. A. F. (2002). Mix-ups and mycoplasma: The enemies within. Leuk Res 26, 329-333. doi:10.1016/S0145-2126(01)00136-9

Duval, K., Grover, H., Han, L. H. et al. (2017). Modeling physiological events in 2D vs. 3D cell culture. Physiology 32, 266277. doi:10.1152/physiol.00036.2016

EMA (2011). European Medicines Agency "Reflection paper on stem cell-based medicinal products”. EMA/CAT/571134/2009. http://www.ema.europa.eu/docs/en_GB/document_library/ Scientific_guideline/2011/02/WC500101692.pdf

EMA (2014). European Medicines Agency "Guideline on process validation for the manufacture of biotechnology-derived active substances and data to be provided in the regulatory submission". EMA/CHMP/BWP/187338/2014. http://www. ema.europa.eu/docs/en_GB/document_library/Scientific_ guideline/2016/04/WC500205447.pdf

Eskes, C., Boström, A.-C., Bowe, G. et al. (2017). Good cell culture practices \& in vitro toxicology. Toxicol In Vitro 45, 272-277. doi:10.1016/j.tiv.2017.04.022

Fatehullah, A., Tan, S. H. and Barker, N. (2016). Organoids as an in vitro model of human development and disease. Nat Cell Biol 18, 246-254. doi:10.1038/ncb3312
Fatica, A. and Bozzoni, I. (2014). Long non-coding RNAs: New players in cell differentiation and development. Nat Rev Genet 15, 7-21. doi:10.1038/nrg3606

Ferrario, D., Brustio, R. and Hartung, T. (2014). Glossary of reference terms for alternative test methods and their validation. ALTEX 31, 319-335. doi:10.14573/altex.140331

Frankart, A., Malaisse, J., De Vuyst, E. et al. (2012). Epidermal morphogenesis during progressive in vitro $3 \mathrm{D}$ reconstruction at the air-liquid interface. Exp Dermatol 21, 871-875. doi:10.1111/exd.12020

Fricain, J. C., De Olivera, H., Devillard, R. et al. (2017). (3D bioprinting in regenerative medicine and tissue engineering). Med Sci (Paris) 33, 52-59. doi:10.1051/medsci/20173301009

Fu, Y., Foden, J. A., Khayter, C. et al. (2013). High-frequency off-target mutagenesis induced by CRISPR-Cas nucleases in human cells. Nat Biotechnol 31, 822-826. doi:10.1038/nbt.2623

Fu, Y., Sander, J. D., Reyon, D. et al. (2014). Improving CRISPR-Cas nuclease specificity using truncated guide RNAs. Nat Biotechnol 32, 279-284. doi:10.1038/nbt.2808

Galietta, L. J., Haggie, P. M. and Verkman, A. S. (2001). Green fluorescent protein-based halide indicators with improved chloride and iodide affinities. FEBS Lett 499, 220-224. doi:10.1016/S0014-5793(01)02561-3

Ghaemmaghami, A. M., Hancock, M. J., Harrington, H. et al. (2012). Biomimetic tissues on a chip for drug discovery. Drug Discov Today 17, 173-181. doi:10.1016/j.drudis.2011.10.029

Goldberg, I. G., Allan, C., Burel, J. M. et al. (2005). The open microscopy environment (OME) data model and XML file: Open tools for informatics and quantitative analysis in biological imaging. Genome Biol 6, R47. doi:10.1186/gb-20056-5-r47

Gonzales, F., Boué, S. and Izpisúa Belmonte, J. C. (2011). Methods for making induced pluripotent stem cells:reprogramming à la carte. Nat Rev Genet 12, 231-242. doi:10.1038/nrg2937

Gonzalez, F., Zhu, Z., Shi, Z. D. et al. (2014). An iCRISPR Platform for rapid, multiplexable, and inducible genome editing in human pluripotent stem cells. Cell Stem Cell 15, 215-226. doi:10.1016/j.stem.2014.05.018

Gropp, M., Itsykson, P., Singer, O. et al. (2003). Stable genetic modification of human embryonic stem cells by lentiviral vectors. Mol Ther 7, 281-287. doi:10.1016/S15250016(02)00047-3

Gruh, I., Wunderlich, S., Winkler, M. et al. (2008). Human CMV immediate-early enhancer: A useful tool to enhance cell-type-specific expression from lentiviral vectors. $J$ Gene Med 10, 21-32. doi:10.1002/jgm.1122

Gstraunthaler, G. and Hartung, T. (1999). Bologna declaration toward good cell culture practice. Altern Lab Anim 27, 206.

Hartung, T., Balls, M., Bardouille, C. et al. (2002). Good cell culture practice. ECVAM good cell culture practice task force report 1. Altern Lab Anim 30, 407-414.

Hartung, T. (2007). Food for thought ... on cell culture. ALTEX 24, 143-152. doi:10.14573/altex.2007.3.143

Hartung, T. (2014). 3D - A new dimension of in vitro research. Adv Drug Deliv Rev 69-70, vi. doi:10.1016/j.addr.2014.04.003 
Hartung, T. (2017). Perspectives on in vitro to in vivo extrapolations. J Appl In Vitro Toxicol, in press. doi:10.1089/ aivt.2016.0026

Haycock, J. W. (2011). 3D cell culture: A review of current approaches and techniques. Methods Mol Biol 695, 1-15. doi:10.1007/978-1-60761-984-0_1

Hogberg, H. T., Bressler, J., Christian, K. M. et al. (2013). Toward a 3D model of human brain development for studying gene/environment interactions. Stem Cell Res Ther 4, Suppl 1, S4. doi:10.1186/scrt365

Hong, N., Yang, G. H., Lee, J. and Kim, G. (2017). 3D bioprinting and its in vivo applications. J Biomed Mater Res B Appl Biomater 106, 444-459. doi:10.1002/jbm.b.33826

Hou, P., Li, Y., Zhang, X. et al. (2013). Pluripotent stem cells induced from mouse somatic cells by small-molecule compounds. Science 341, 651-654. doi:10.1126/science.1239278

Howden, S. E., Maufort, J. P., Duffin, B. M. et al. (2015). Simultaneous reprogramming and gene correction of patient fibroblasts. Stem Cell Reports 5, 1109-1118. doi:10.1016/j. stemcr.2015.10.009

Hsu, P. D., Scott, D. A., Weinstein, J. A. et al. (2013). DNA targeting specificity of RNA-guided Cas9 nucleases. Nat Biotechnol 31, 827-832. doi:10.1038/nbt.2647

Huh, D., Hamilton, G. A. and Ingber, D. E. (2011). From 3D cell culture to organs-on-chips. Trends Cell Biol 21, 745-754. doi:10.1016/j.tcb.2011.09.005

Jennings, P., Aschauer, L., Wilmes, A. and Gstraunthaler, G. (2014). Renal cell culture. In A. Bal-Price and P. Jennings (eds.), In Vitro Toxicology Systems, Methods in Pharmacology and Toxicology (79-101). New York: Springer. doi:10.1007/978-1-4939-0521-8_4

Jennings, P. (2015). The future of in vitro toxicology. Toxicol In Vitro 29, 1217-1221. doi:10.1016/j.tiv.2014.08.011

Kameoka, S., Babiarz, J., Kolaja, K. and Chiao, E. (2014). A high-throughput screen for teratogens using human pluripotent stem cells. Toxicol Sci 137, 76-90. doi:10.1093/toxsci/ kft239

Kilic, O., Pamies, D., Lavell, E. et al. (2016). Brain-on-a-chip model enables analysis of human neuronal differentiation and chemotaxis. Lab Chip 16, 4152-4162. doi:10.1039/ C6LC00946H

Kim, J. H., Kurtz, A., Yuan, B. Z. et al. (2017). Report of the international stem cell banking initiative workshop activity: Current hurdles and progress in seed-stock banking of human pluripotent stem cells. Stem Cells Transl Med 6, 1956-1962. doi:10.1002/sctm.17-0144

Kim, K., Doi, A., Wen, B. et al. (2010). Epigenetic memory in induced pluripotent stem cells. Nature 467, 285-290. doi:10.1038/nature09342

Kimbrel, E. A. and Lanza, R. (2015). Current status of pluripotent stem cells: Moving the first therapies to the clinic. Nat Rev Drug Discov 14, 681-692. doi:10.1038/nrd4738

King, N. M. and Perrin, J. (2014). Ethical issues in stem cell research and therapy. Stem Cell Res Ther 5, 85. doi:10.1186/ scrt474
Kleensang, A,. Vantangoli, M., Odwin-DaCosta, S. et al. (2016). Genetic variability in a frozen batch of MCF-7 cells invisible in routine authentication affecting cell function. Sci Rep 6, 28994-28994. doi:10.1038/srep28994

Knight, E. and Przyborski, S. (2015). Advances in 3D cell culture technologies enabling tissue-like structures to be created in vitro. J Anat 227, 746-756. doi:10.1111/joa.12257

Kolaja, K. (2014). Stem cells and stem cell-derived tissues and their use in safety assessment. J Biol Chem 289, 4555-4561. doi:10.1074/jbc.R113.481028

Kyttälä, A., Moraghebi, R., Valensisi, C. et al. (2016). Genetic variability overrides the impact of parental cell type and determines iPSC differentiation potential. Stem Cell Reports 6, 200-212. doi:10.1016/j.stemcr.2015.12.009

Lancaster, M. A., Renner, M., Martin, C. A. et al. (2013). Cerebral organoids model human brain development and microcephaly. Nature 501, 373-379. doi:10.1038/nature12517

Li, X. J., Valadez, A. V., Zuo, P. and Nie, Z. (2012). Microfluidic 3D cell culture: Potential application for tissue-based bioassays. Bioanalysis 4, 1509-1525. doi:10.4155/bio.12.133

Li, Z. and Cui, Z. (2014). Three-dimensional perfused cell culture. Biotechnol Adv 32, 243-254. doi:10.1016/j.biotechadv. 2013.10.006

Liang, G. and Zhang, Y. (2013a). Embryonic stem cell and induced pluripotent stem cell: An epigenetic perspective. Cell Res 23, 49-69. doi:10.1038/cr.2012.175

Liang, G. and Zhang, Y. (2013b). Genetic and epigenetic variations in iPSCs: Potential causes and implications for application. Stem Cell 13, 149-159. doi:10.1016/j. stem.2013.07.001

Liu, J., Jones, K. L., Sumer, H. and Verma, P. J. (2009). Stable transgene expression in human embryonic stem cells after simple chemical transfection. Mol Reprod Dev 76, 580-586. doi:10.1002/mrd.20983

Mali, P., Aach, J., Stranges, P. B. et al. (2013). CAS9 transcriptional activators for target specificity screening and paired nickases for cooperative genome engineering. Nat Biotechnol 31, 833-838. doi:10.1038/nbt.2675

Malik, N. and Rao, M. S. (2013). A review of the methods for human iPSC derivation. Methods Mol Biol 997, 23-33. doi:10.1007/978-1-62703-348-0_3

Marx, U. (2012). Trends in cell culture technology. Adv Exp Med Biol 745, 26-46. doi:10.1007/978-1-4614-3055-1_3

Marx, U., Walles, H., Hoffmann, S. et al. (2012). "Human-on-achip" developments: A translational cutting-edge alternative to systemic safety assessment and efficiency evaluation of substances in laboratory animals and man? Altern Lab Anim 40, 235-257.

Marx, U., Andersson, T. B., Bahinski, A. et al. (2016). Biology-inspired microphysiological system approaches to solve the prediction dilemma of substance testing using animals. ALTEX 33, 272-321. doi:10.14573/altex.1603161

Maschmeyer, I., Hasenberg, T., Jaenicke, A. et al. (2015). Chipbased human liver-intestine and liver-skin co-cultures - A first step toward systemic repeated dose substance testing 
in vitro. Eur J Pharm Biopharm 95, 77-87. doi:10.1016/j. ejpb.2015.03.002

Merkert, S., Wunderlich, S., Bednarski, C. et al. (2014). Efficient designer nuclease-based homologous recombination enables direct PCR screening for footprintless targeted human pluripotent stem cells. Stem Cell Reports 2, 107-118. doi:10.1016/j. stemcr.2013.12.003

Merkert, S. and Martin, U. (2016). Targeted genome engineering using designer nucleases: State of the art and practical guidance for application in human pluripotent stem cells. Stem Cell Res 16, 377-386. doi:10.1016/j.scr.2016.02.027

Miller, J. C., Tan, S., Qiao, G. et al. (2011). A TALE nuclease architecture for efficient genome editing. Nat Biotechnol 29, 143-148. doi:10.1038/nbt. 1755

Monzel, A. S., Smits, L. M., Hemmer, K. et al. (2017). Derivation of human midbrain-specific organoids from neuroepithelial stem cells. Stem Cell Reports 8, 1144-1154. doi:10.1016/j. stemcr.2017.03.010

Moreno, E. L., Hachi, S., Hemmer, K. et al. (2015). Differentiation of neuroepithelial stem cells into functional dopaminergic neurons in 3D microfluidic cell culture. Lab Chip 15, 24192428. doi:10.1039/C5LC00180C

Müller, F. J., Schuldt, B. M., Williams, R. et al. (2011). A bioinformatic assay for pluripotency in human cells. Nat Methods 8, 315-317. doi:10.1038/nmeth. 1580

Nielen, M. G., de Vries, S. A. and Geijsen, N. (2013). European stem cell research in legal shackles. EMBO J 32, 3107-3111. doi:10.1038/emboj.2013.249

Page, H., Flood, P. and Reynaud, E. G. (2013). Three-dimensional tissue cultures: Current trends and beyond. Cell Tissue Res 352, 123-131. doi:10.1007/s00441-012-1441-5

Pamies, D. and Hartung, T. (2017). $21^{\text {st }}$ century cell culture for $21^{\text {st }}$ century toxicology. Chem Res Toxicol 30, 43-52. doi:10.1021/acs.chemrestox.6b00269

Pamies, D., Bal-Price, A., Simeonov, A. et al. (2017a). Good cell culture practice for stem cells and stem-cell-derived models. ALTEX 34, 95-132. doi:10.14573/altex.1607121

Pamies, D., Barreras, P., Block, K. et al. (2017b). A human brain microphysiological system derived from induced pluripotent stem cells to study neurological diseases and toxicity. ALTEX 34, 362-376. doi:10.14573/altex.1609122

Passier, R., Orlova, V. and Mummery, C. (2016). Complex tissue and disease modeling using hiPSCs. Cell Stem Cell 18, 309321. doi:10.1016/j.stem.2016.02.011

Pattanayak, V., Lin, S., Guilinger, J. P. et al. (2013). Highthroughput profiling of off-target DNA cleavage reveals RNA-programmed Cas9 nuclease specificity. Nat Biotechnol 31, 839-843. doi:10.1038/nbt.2673

Pera, M. F., de Wert, G., Dondorp, W. et al. (2015). What if stem cells turn into embryos in a dish? Nat Methods 12, 917-919. doi:10.1038/nmeth.3586

Perestrelo, A. R., Aguas, A. C., Rainer, A. and Forte, G. (2015). Microfluidic organ/body-on-a-chip devices at the convergence of biology and microengineering. Sensors 15, 31142-31170. doi:10.3390/s151229848
Pettersen, E. O., Larsen, L. H., Ramsing, N. B. and Ebbesen, P. (2005). Pericellular oxygen depletion during ordinary tissue culturing, measured with oxygen microsensors. Cell Prolif 38, 257-267. doi:10.1111/j.1365-2184.2005.00345.x

Pinheiro de Oliveira, T. F., Fonseca, A. A., Camargos, M. F. et al. (2013). Detection of contaminants in cell cultures, sera and trypsin. Biologicals 41, 407-414. doi:10.1016/j.biologicals. 2013.08.005

Plath, K. and Lowry, W. E. (2011). Progress in understanding reprogramming to the induced pluripotent state. Nat Rev Genet 12, 253-265. doi: $10.1038 / \mathrm{nrg} 2955$

Porteus, M. H. and Carroll, D. (2005). Gene targeting using zinc finger nucleases. Nat Biotechnol 23, 967-973. doi:10.1038/ nbt1125

Prinz, F., Schlange, T. and Asadullah, K. (2011). Believe it or not: How much can we rely on published data on potential drug targets? Nat Rev Drug Discov 10, 712. doi:10.1038/nrd3439-c1

Ravi, M., Paramesh, V., Kaviya, S. R. et al. (2015). 3D cell culture systems: Advantages and applications. J Cell Physiol 230, 16-26. doi:10.1002/jcp.24683

Rebelo, S. P., Dehne, E. M., Brito, C. et al. (2016). Validation of bioreactor and human-on-a-chip devices for chemical safety assessment. Adv Exp Med Biol 856, 299-316. doi:10.1007/9783-319-33826-2_12

Rempel, E., Hoelting, L., Waldmann, T. et al. (2015). A transcriptome-based classifier to identify developmental toxicants by stem cell testing: Design, validation and optimization for histone deacetylase inhibitors. Arch Toxicol 89, 1599-1618. doi:10.1007/s00204-015-1573-y

Reubinoff, B. E., Pera, M. F., Fong, C. Y. et al. (2000). Embryonic stem cell lines from human blastocysts: Somatic differentiation in vitro. Nat Biotechnol 18, 399-404. doi:10.1038/74447

Roth, A. and Singer, T. (2014). The application of 3D cell models to support drug safety assessment: Opportunities \& challenges. Adv Drug Deliv Rev 69-70, 179-189. doi:10.1016/j. addr.2013.12.005

Rouet, P., Smih, F. and Jasin, M. (1994). Expression of a site-specific endonuclease stimulates homologous recombination in mammalian cells. Proc Natl Acad Sci U S A 91, 6064-6068. doi:10.1073/pnas.91.13.6064

Sakurai, K., Kurtz, A., Stacey, G. et al. (2016). First proposal of minimum information about a cellular assay for regenerative medicine (MIACARM). Stem Cells Transl Med 5, 1345-1361. doi:10.5966/sctm.2015-0393

Sato, T., Vries, R. G., Snippert, H. J. et al. (2009). Single Lgr5 stem cells build crypt-villus structures in vitro without a mesenchymal niche. Nature 459, 262-265. doi:10.1038/ nature 07935

Schlaeger, T. M., Daheron, L., Brickler, T. R. et al. (2015). A comparison of non-integrating reprogramming methods. Nat Biotechnol 33, 58-63. doi:10.1038/nbt.3070

Schwanke, K., Merkert, S., Kempf, H. et al. (2014). Fast and efficient multitransgenic modification of human pluripotent stem cells. Hum Gene Ther Methods 25, 136-153. doi:10.1089/ hgtb.2012.248 
Scott, C. W., Peters, M. F. and Dragan, Y. P. (2013). Human induced pluripotent stem cells and their use in drug discovery for toxicity testing. Toxicol Lett 219, 49-58. doi:10.1016/j. toxlet.2013.02.020

Seltmann, S., Lekschas, F., Muller, R. et al. (2016). hPSCreg The human pluripotent stem cell registry. Nucleic Acids Res 44, D757-763. doi:10.1093/nar/gkv963

Siemen, H., Nix, M., Endl, E. et al. (2005). Nucleofection of human embryonic stem cells. Stem Cells Dev 14, 378-383. doi:10.1089/scd.2005.14.378

Slaymaker, I. M., Gao, L., Zetsche, B. et al. (2016). Rationally engineered Cas9 nucleases with improved specificity. Science 351, 84-88. doi:10.1126/science.aad5227

Soares, F. A., Sheldon, M., Rao, M. et al. (2014). International coordination of large-scale human induced pluripotent stem cell initiatives: Wellcome Trust and ISSCR workshops white paper. Stem Cell Reports 3, 931-939. doi:10.1016/j.stemcr.2014.11.006

Sommer, C. A., Stadtfeld, M., Murphy, G. J. et al. (2009). Induced pluripotent stem cell generation using a single lentiviral stem cell cassette. Stem Cells 27, 543-549. doi:10.1634/stemcells.2008-1075

Stacey, G., Doyle, A. and Hambleton, P. (eds.) (1998). Safety in Cell and Tissue Culture. Springer. doi:10.1007/978-94-0114916-7

Stacey, G. (2012). Current developments in cell culture technology. Adv Exp Med Biol 745, 1-13. doi:10.1007/978-1-46143055-1_1

Stacey, G. N., Coecke, S., Price, A. et al. (2016). Ensuring the quality of stem cell derived models for toxicity testing. $A d v$ Exp Med Biol 856, 259-297. doi:10.1007/978-3-319-338262_11

Subramanyam, D., Lamouille, S., Judson, R. L. et al. (2011). Multiple targets of miR-302 and miR-372 promote reprogramming of human fibroblasts to induced pluripotent stem cells. Nat Biotechnol 29, 443-448. doi:10.1038/nbt.1862

Takahashi, K. and Yamanaka, S. (2006). Induction of pluripotent stem cells from mouse embryonic and adult fibroblast cultures by defined factors. Cell 126, 663-676. doi:10.1016/j. cell.2006.07.024

Takahashi, K., Tanabe, K., Ohnuki, M. et al. (2007). Induction of pluripotent stem cells from adult human fibroblasts by defined factors. Cell 131, 861-872. doi:10.1016/j.cell.2007.11.019

Takebe, T., Zhang, R. R., Koike, H. et al. (2014). Generation of a vascularized and functional human liver from an iPSC-derived organ bud transplant. Nat Protoc 9, 396-409. doi:10.1038/ nprot.2014.020

Tallini, Y. N., Ohkura, M., Choi, B. R. et al. (2006). Imaging cellular signals in the heart in vivo: Cardiac expression of the high-signal $\mathrm{Ca}^{2+}$ indicator GCaMP2. Proc Natl Acad Sci U S A 103, 4753-4758. doi:10.1073/pnas.0509378103

Templin, C., Zweigerdt, R., Schwanke, K. et al. (2012). Transplantation and tracking of human-induced pluripotent stem cells in a pig model of myocardial infarction: Assessment of cell survival, engraftment, and distribution by hybrid single photon emission computed tomography/computed tomogra- phy of sodium iodide symporter transgene expression. Circulation 126, 430-439. doi:10.1161/CIRCULATIONAHA. 111.087684

Thomson, J. A., Itskovitz-Eldor, J., Shapiro, S. S. et al. (1998). Embryonic stem cell lines derived from human blastocysts. Science 282, 1145-1147. doi:10.1126/science.282.5391.1145

Tsaioun, K., Blaauboer, B. J. and Hartung, T. (2016). Evidence-based absorption, distribution, metabolism, excretion and toxicity (ADMET) and the role of alternative methods. ALTEX 33, 343-358. doi:10.14573/altex.1610101

van der Valk, J., Bieback, K., Buta, C. et al. (2018). Fetal bovine serum (FBS): Past - present - future. ALTEX 35, 99-118. doi:10.14573/altex.1705101

van Duinen, V., Trietsch, S. J., Joore, J. et al. (2015). Microfluidic 3D cell culture: From tools to tissue models. Curr Opin Biotechnol 35, 118-126. doi:10.1016/j.copbio.2015.05.002

van Vliet, E. (2011). Current standing and future prospects for the technologies proposed to transform toxicity testing in the $21^{\text {st }}$ century. ALTEX 28, 17-44. doi:10.14573/altex.2011.1.017 van Vliet, E., Daneshian, M., Beilmann, M. et al. (2014). Current approaches and future role of high content imaging in safety sciences and drug discovery. ALTEX 31, 479-493. doi:10.14573/altex.1405271

Vasquez, K. M., Marburger, K., Intody, Z. and Wilson, J. H. (2001). Manipulating the mammalian genome by homologous recombination. Proc Natl Acad Sci US A 98, 8403-8410. doi:10.1073/pnas.111009698

Veres, A., Gosis, B. S., Ding, Q. et al. (2014). Low incidence of off-target mutations in individual CRISPR-Cas9 and TALEN targeted human stem cell clones detected by whole-genome sequencing. Cell Stem Cell 15, 27-30. doi:10.1016/j. stem.2014.04.020

Verkman, A. S., Lukacs, G. L. and Galietta, L. J. (2006). CFTR chloride channel drug discovery - Inhibitors as antidiarrheals and activators for therapy of cystic fibrosis. Curr Pharm Des 12, 2235-2247. doi:10.2174/138161206777585148

Waldman, A. S. (1992). Targeted homologous recombination in mammalian cells. Crit Rev Oncol Hematol 12, 49-64. doi:10.1016/1040-8428(92)90064-W

Wang, G., McCain, M. L., Yang, L. et al. (2014). Modeling the mitochondrial cardiomyopathy of Barth syndrome with induced pluripotent stem cell and heart-on-chip technologies. Nat Med 20, 616-623. doi:10.1038/nm.3545

Ware, B. R. and Khetani, S. R. (2017). Engineered liver platforms for different phases of drug development. Trends Biotechnol 35, 172-183. doi:10.1016/j.tibtech.2016.08.001

Welsh, M. J. and Smith, A. E. (1993). Molecular mechanisms of CFTR chloride channel dysfunction in cystic fibrosis. Cell 73, 1251-1254. doi:10.1016/0092-8674(93)90353-R

West, P. R., Weir, A. M., Smith, A. M. et al. (2010). Predicting human developmental toxicity of pharmaceuticals using human embryonic stem cells and metabolomics. Toxicol Appl Pharmacol 247, 18-27. doi:10.1016/j.taap.2010.05.007

WHO (2010). Recommendations for the evaluation of animal cell cultures as substrates for the manufacture of biological 
medicinal products, Adopted by the $61^{\text {st }}$ meeting of the WHO Expert Committee on Biological Standardization, 18 to 22 October 2010, WHO, Geneva. http://www.who.int/biologicals/Cell_Substrates_clean_version_18_April.pdf (accessed 08.10.2017).

Wieser, M., Francisci, T., Lackner, D. et al. (submitted). CD46 knock-out using CRISPR/Cas9 editing of hTERT immortalized human cells.

Wilmer, M. J., Ng, C. P., Lanz, H. L. et al. (2016). Kidneyon-a-chip technology for drug-induced nephrotoxicity screening. Trends Biotechnol 34, 156-170. doi:10.1016/j. tibtech.2015.11.001

Yoon, N. D., Lee, K. H., Lee, J. and Lee, S. H. (2015). 3D liver models on a microplatform: Well-defined culture, engineering of liver tissue and liver-on-a-chip. Lab Chip 15, 3822-3837. doi:10.1039/C5LC00611B

Ye, F., Chen, C., Qin, J. et al. (2015). Genetic profiling reveals an alarming rate of cross-contamination among human cell lines used in China. FASEB J 29, 4268-4272. doi:10.1096/ fj.14-266718

Yu, C., Liu, Y., Ma, T. et al. (2015). Small molecules enhance CRISPR genome editing in pluripotent stem cells. Cell Stem Cell 16, 142-147. doi:10.1016/j.stem.2015.01.003

Yu, J., Vodyanik, M. A., Smuga-Otto, K. et al. (2007). Induced pluripotent stem cell lines derived from human somatic cells. Science 318, 1917-1920. doi:10.1126/science.1151526
Zhang, C. and van Noort, D. (2011). Cells in microfluidics. Top Curr Chem 304, 295-321. doi:10.1007/128_2011_147

Zhang, J., Wei, X., Zeng, R. et al. (2017). Stem cell culture and differentiation in microfluidic devices toward organ-on-achip. Future Sci OA 3, FSO187. doi:10.4155/fsoa-2016-0091

\section{Conflict of interest}

Thomas Hartung is the founder of Organome LLC, Baltimore, US, which has licensed brain organoid technologies from Johns Hopkins to make them commercially available. He also consults AstraZeneca on modern cell culture models. Regina Grillari is co-founder and chief technology officer of Evercyte $\mathrm{GmbH}$, Vienna, Austria, which has focused on the commercialization of human hTERT immortalized cell lines for in vitro testing. Andras Dinnyes is the founder of BioTalentum Ltd, HU, a stem cell company that develops human iPSC-based toxicity assays and disease models. Robert Passier is a co-founder of Pluriomics, Leiden, T he Netherlands, which uses hiPSC-derived cardiomyocytes for safety pharmacology testing and cardiovascular drug efficacy screening.

\section{Acknowledgements}

This work was supported by EU H2020 project EU-ToxRisk (H2020-PHC-2015-681002 to Andras Dinnyes, Marcel Leist, Mardas Daneshian and Thomas Hartung). 